\title{
Organic matter cycling along geochemical, geomorphic, and disturbance gradients in forest and cropland of the African Tropics - project TropSOC database version 1.0
}

\author{
Sebastian Doetterl ${ }^{1,2}$, Rodrigue K. Asifiwe ${ }^{6}$, Geert Baert ${ }^{4}$, Fernando Bamba ${ }^{6}$, Marijn Bauters ${ }^{3,4}$, \\ Pascal Boeckx ${ }^{3}$, Benjamin Bukombe ${ }^{2}$, Georg Cadisch ${ }^{5}$, Matthew Cooper ${ }^{8}$, Landry N. Cizungu ${ }^{6}$, \\ Alison Hoyt ${ }^{7}$, Clovis Kabaseke ${ }^{8}$, Karsten Kalbitz ${ }^{9}$, Laurent Kidinda ${ }^{9}$, Annina Maier ${ }^{1}$, \\ Moritz Mainka $^{2,14}$, Julia Mayrock ${ }^{2}$, Daniel Muhindo ${ }^{6}$, Basile B. Mujinya ${ }^{10}$, Serge M. Mukotanyi ${ }^{6}$, \\ Leon Nabahungu ${ }^{12}$, Mario Reichenbach ${ }^{2}$, Boris Rewald ${ }^{11}$, Johan Six ${ }^{1}$, Anna Stegmann ${ }^{2}$, \\ Laura Summerauer $^{1}$, Robin Unseld ${ }^{2}$, Bernard Vanlauwe ${ }^{12}$, Kristof Van Oost ${ }^{13,15}$, Kris Verheyen ${ }^{4}$, \\ Cordula Vogel $^{9}$, Florian Wilken $^{1,2}$, and Peter Fiener ${ }^{2}$ \\ ${ }^{1}$ Department of Environmental System Sciences, ETH Zurich, 8092 Zürich, Switzerland \\ ${ }^{2}$ Institute of Geography, Augsburg University, Augsburg, Germany \\ ${ }^{3}$ Department of Green Chemistry and Technology, Ghent University, Ghent, Belgium \\ ${ }^{4}$ Department of Environment, Ghent University, Ghent, Belgium \\ ${ }^{5}$ Institute of Plant Production and Agroecology in the Tropics and Subtropics, \\ University of Hohenheim, Stuttgart, Germany \\ ${ }^{6}$ Faculty of Agricultural Sciences, Université Catholique de Bukavu, Bukavu, DR Congo \\ ${ }^{7}$ Department of Biogeochemical Processes, Max Planck Institute for Biogeochemistry, Jena, Germany \\ ${ }^{8}$ School of Agriculture and Environmental Sciences, Mountains of the Moon University, Fort Portal, Uganda \\ ${ }^{9}$ Chair of Soil Resources and Land Use, Institute of Soil Science and Site Ecology, \\ TU Dresden, Tharandt, Germany \\ ${ }^{10}$ Biogeochemistry and Ecology of Tropical Soils and Ecosystems Unit, University of Lubumbashi, \\ Lubumbashi, DR Congo \\ ${ }^{11}$ Department of Forest and Soil Sciences, University of Natural Resources and Life Sciences \\ (BOKU), Vienna, Austria \\ ${ }^{12}$ International Institute of Tropical Agriculture, Central Africa and Natural Resource Management, \\ CGIAR, Nairobi, Kenya \\ ${ }^{13}$ Earth and Life Institute, UCLouvain, Louvain-la-Neuve, Belgium \\ ${ }^{14}$ Institut National pour L'Etude et la Recherche Agronomiques (INERA), Mulungu, DR Congo \\ ${ }^{15}$ Fonds National de la Recherche Scientifique (FNRS), Brussels Belgium \\ Correspondence: Sebastian Doetterl (sdoetterl@usys.ethz.ch)
}

Received: 1 March 2021 - Discussion started: 23 April 2021

Revised: 5 July 2021 - Accepted: 7 July 2021 - Published: 25 August 2021

\begin{abstract}
The African Tropics are hotspots of modern-day land use change and are, at the same time, of great relevance for the cycling of carbon $(\mathrm{C})$ and nutrients between plants, soils, and the atmosphere. However, the consequences of land conversion on biogeochemical cycles are still largely unknown as they are not studied in a landscape context that defines the geomorphic, geochemical, and pedological framework in which biological processes take place. Thus, the response of tropical soils to disturbance by erosion and land conversion is one of the great uncertainties in assessing the carrying capacity of tropical landscapes to grow food for future generations and in predicting greenhouse gas fluxes from soils to the atmosphere and, hence, future earth system dynamics.
\end{abstract}


Here we describe version 1.0 of an open-access database created as part of the project "Tropical soil organic carbon dynamics along erosional disturbance gradients in relation to variability in soil geochemistry and land use" (TropSOC). TropSOC v1.0 (Doetterl et al., 2021, https://doi.org/10.5880/fidgeo.2021.009) contains spatially and temporally explicit data on soil, vegetation, environmental properties, and land management collected from 136 pristine tropical forest and cropland plots between 2017 and 2020 as part of monitoring and sampling campaigns in the eastern Congo Basin and the East African Rift Valley system. The results of several laboratory experiments focusing on soil microbial activity, $\mathrm{C}$ cycling, and $\mathrm{C}$ stabilization in soils complement the dataset to deliver one of the first landscape-scale datasets to study the linkages and feedbacks between geology, geomorphology, and pedogenesis as controls on biogeochemical cycles in a variety of natural and managed systems in the African Tropics.

The hierarchical and interdisciplinary structure of the TropSOC database allows linking of a wide range of parameters and observations on soil and vegetation dynamics along with other supporting information that may also be measured at one or more levels of the hierarchy. TropSOC's data mark a significant contribution to improve our understanding of the fate of biogeochemical cycles in dynamic and diverse tropical African (agro-)ecosystems. TropSOC v1.0 can be accessed through the Supplement provided as part of this paper or as a separate download via the websites of the Congo Biogeochemistry Observatory and GFZ Data Services where version updates to the database will be provided as the project develops.

\section{Rationale for project TropSOC}

\subsection{Changing tropical environments in Africa}

Tropical ecosystems provide many services of global importance. Tropical forests are among the largest terrestrial carbon (C) reservoirs and show some of the highest levels of biodiversity (Losos and Leigh, 2004; Pan et al., 2011). At the same time, tropical landscapes are among the most dynamic regions worldwide and hotspots of modern day land use change (Hansen et al., 2013) as they have to provide food for some of the poorest yet fastest growing populations on the planet. In particular, the African continent is facing huge environmental and societal challenges with a projected population growth of $400 \%$ by the end of this century (Gerland et al., 2014), much of it happening in (sub)tropical sub-Saharan Africa. In consequence, forested landscapes in tropicalAfrica are currently facing unprecedented levels of land conversion and land degradation, accompanied by decreasing soil fertility (UNESCO and WHC, 2010). At the same time, unlike other tropical regions of the world where deforestation is driven by the extension of commodity plantations and commercial logging, much of the deforestation in tropical African countries is driven by smallholder farms that apply slash and burn practices for subsistence farming with little alternatives to provide food for their families (Curtis et al., 2018; Tyukavina et al., 2018). As a result, deforestation and soil degradation have accelerated greatly since the second half of the 20th century, with soil erosion in particular, emerging as the main driver of soil degradation.

Today, erosion rates of tropical agricultural land globally are estimated at approx. 10.4 billion tons of soil per year and 0.2 billion tons of $\mathrm{C}$ per year. Tropical agricultural soil erosion therefore represents about half of the annual agricultural erosion globally while only representing about one third of global cropland (Doetterl et al., 2012). An exemplary region to observe the consequences of land use change on soil resources and biogeochemical cycles in the tropical African regional context is the African Great Lakes region and, in particular, East African Rift Valley system along the borders between the Democratic Republic of the Congo (DRC), Burundi, Rwanda, and Uganda.

The region is a model for the complex interplay of socioeconomic factors and their consequences for environmental systems in the tropics. One of the highest human fertility rates globally (e.g., recent estimates for the last decade range from 7.3 to 7.7 children per woman in the province of South Kivu, eastern DRC) (Dumbaugh et al., 2018) is leading to massive population growth in the region, largely relying on local food and energy resources. Ridden by conflict and open warfare in the 1990s and early 2000s, population growth in the region is further aggravated by refugees from remote areas settling in nearby safer, larger cities in the region (Kujirakqinja et al., 2010). Consequently, massive deforestation of upland forests for firewood and cropland expansion is taking place (Hansen et al., 2013), leading to large erosional soil fluxes and consequential soil degradation threatening soil quality (Karamage et al., 2016). Once conversion to agricultural land has taken place, soil conservation measures could counteract the loss of soil quality (Veldkamp et al., 2020). However, these measures are rare in the eastern Congo Basin due to the poverty of subsistence farmers, socioeconomic instability, and a lack of governmental intervention (Heri-Kazi Bisimwa and Bielders, 2020). Soil tillage and harvesting further degrade the nutrient-containing litter and topsoil layers. Consequently, fields often have to be abandoned after only a decade of use and recover poorly (Carreño-Rocabado et al., 
2016; Ewel et al., 1991; Hattori et al., 2019; Heinrich et al., 2020; Kleinman et al., 1996; Lawrence et al., 2010).

\subsection{Tropical soils responding to disturbance}

With the expansion of cropland into forested landscapes, soil erosion rates are expected to continue to increase. Soil erosion will undoubtedly have an impact on biogeochemical cycles and will change the input, storage, and exchange of $\mathrm{C}$ between soils and the atmosphere, as well as the flux of nutrients between plants and soils in tropical systems in the region. To understand how tropical soils and ecosystems respond to erosional disturbance, it is necessary to consider the combined effects of climate, geology, topography, soil formation, biological processes, and human disturbance. To date, no study on the interrelationship of these controls on biogeochemical cycles has been carried out in tropical ecosystems. However, studies carried out in other regions have shown that controls on soil $\mathrm{C}$ dynamics, for example, are highly interlinked (Doetterl et al., 2015; Hobley and Wilson, 2016; Nadeu et al., 2015).

Soil redistribution as a consequence of erosion also changes the functionality of landscape units. For example, soil degradation on hillslopes is matched by a buildup of sediment deposits in valley bottoms where $\mathrm{C}$ and nutrient-rich soil can be rapidly buried in subsoils under new sediments. While this consequence of deforestation can lead to an increase in the residence time of $\mathrm{C}$ due to slower microbial C turnover in buried soil (Van Oost et al., 2007; Doetterl et al., 2012; Alcántara et al., 2017), important nutrients are now lost to plants, leading to a decrease in biomass productivity (Veldkamp et al., 2020) but also to a general degradation of tropical forest soils, lowering also microbial activity in soils (Sahani and Behera, 2001). Soil redistribution is also known to change the temporal and spatial patterns of soil weathering and affects $C$ stabilization. In agricultural systems, the effects of this pressure can be observed very clearly: erosion removes weathered soil from eroding slopes but also brings the soil weathering front into closer contact with the $\mathrm{C}$ cycle (which occurs primarily in topsoils), thereby affecting carbon, nitrogen, and phosphorus (CNP) cycling and the stabilization of $\mathrm{C}$ with minerals in these systems (e.g., Berhe et al., 2012; Park et al., 2014; Doetterl et al., 2016).

Concerning feedbacks on biogeochemical cycles between soil weathering, erosion will differ significantly not only between natural and disturbed systems but also between systems with differing soil mineral reactivity. Recent advances have shown that mineral reactivity, constrained predominantly by soil weathering and the mineralogy of the soil parent material, has direct control over soil organic carbon, with climate exerting only indirect control through its impact on biogeochemical processes and matter fluxes (Doetterl et al., 2015; Tang and Riley, 2015). However, the exact effects of mineralogy on the temperature sensitivity of microbial decomposer communities and the primary productiv- ity of ecosystems have, to date, not been constrained (Hahm et al., 2014; Tang and Riley, 2015).

\subsection{Importance and outlook of research on the future of tropical biogeochemical cycles}

Tropical Africa is expected to experience great changes to both soil biogeochemical cycling and ecosystem-level carbon $(\mathrm{C})$ fluxes between soil, plants, and the atmosphere with unknown consequences for biogeochemical cycles. Despite decades of recognizing their importance, tropical soils remain among the least studied in the world (Mohr and van Baren, 1954; Mohr et al., 1972; Ssali et al., 1986; Juo and Franzluebbers, 2003). Although a more complete understanding of soil-plant coupling in tropical environments is critical, most of our process understanding of biogeochemical cycling between plant and soil is still derived from temperate regions. However, due to differences in their environmental setting and soil forming history, many tropical soil systems will likely react very differently to soil disturbance and land conversion than temperate soil systems. For example, temperate ecosystems can differ fundamentally in the way nutrients cycle and in the dominating and limiting factors for plant growth (Du et al., 2020). In contrast to soils in the temperate zone, long-lasting chemical weathering has led to a massive depletion of mineral nutrients from soils in many tropical systems, although the remaining available nutrients are very efficiently recycled in natural tropical biospheres (Walker and Syers, 1976; Vitousek, 1984). Hence, any loss of nutrients is therefore a critical disturbance with direct effects on the functioning of tropical (agro-)ecosystems. Recent studies highlight the importance of soil degradation and the change in chemical soil properties that follows land conversion on plant communities in tropical systems (Bauters et al., 2021), organic matter turnover by microbial decomposers (Bukombe et al., 2021), and the stabilization of $\mathrm{C}$ and nutrients in soil of varying mineralogical properties (Reichenbach et al., 2021).

Improving our process understanding of the coupling between soil biogeochemistry and plant responses in the context of tropical land use changes will help to better constrain and define plant-soil interactions in ecosystem and land surface models. Furthermore, insight into plant-soil interactions can help to better inform policy makers and stakeholders in improving land management practices.

\subsection{Objectives and framework}

In the following we aim at providing an overview of the data collected by project TropSOC (Tropical soil organic carbon dynamics along erosional disturbance gradients in relation to variability in soil geochemistry and land use) which is now available to the research community as an open-access database. We give a brief description of the project's design before elaborating on the structure of the database and 
its content. Note that beyond the overview information presented here, more details on methods and sampling designs for each assessed parameter are explained in greater detail in the Supplement accompanying the paper and the database.

The main objective of project TropSOC was to develop a mechanistic understanding of plant and microbial process responses to changing soil properties in the African Tropics, exemplified along land use and erosional and soil geochemical gradients studied in the Congo and the Albertine Rift. Trying to understand biogeochemical cycling affected by human activities in tropical (agro-)ecosystems as a whole, TropSOC had two main foci:

i. investigate how nutrient fluxes and organic matter allocation between tropical soils and plants differ in relation to the controlling factors of geochemistry, topography, and land use;

ii. investigate how the geochemistry of soils and their parent material control, interact with, or mediate the severity of erosional disturbance on $\mathrm{C}$ cycling in tropical soils.

In order to address these objectives, project TropSOC investigates effects on tropical soil biogeochemical cycling and biological responses to variation in soil and environmental properties along three main vectors (Fig. 1): (i) mineralogy of parent material, since it may drive the geochemical features of developed soils which control soil fertility and the potential of soils to stabilize organic matter and nutrients; (ii) landform, since topography may influence water and soil fluxes, particularly erosional soil loss on slopes and soil deposition in valleys; and (iii) vegetation and land cover, since it may control the input to and extraction of organic matter from soil and respond to variation in soil properties and hydrology, as well as mediate the impact of rainfall to induce soil erosion.

Conducted in one of the hotspots of global change - in the Central African Congo Basin and African Great Lakes region - the database described here is the foundation for several papers published as a part of the 2021 special issue Tropical biogeochemistry of soils in the Congo Basin and the African Great Lakes region in SOIL Journal (Bukombe et al., 2021; Summerauer et al., 2021; Reichenbach et al., 2021; Wilken et al., 2021).

\section{Study and sampling design}

\subsection{Study area - climate, topography, land use}

The study area of TropSOC is located in the eastern part of the Democratic Republic of the Congo, Rwanda, and Uganda, in the border region between the Congo and the Nile Basin (Fig. 2). It is largely understudied (Schimel et al., 2015) despite its great significance for the global climate system (Jobbágy and Jackson, 2000; Amundson et al., 2015)

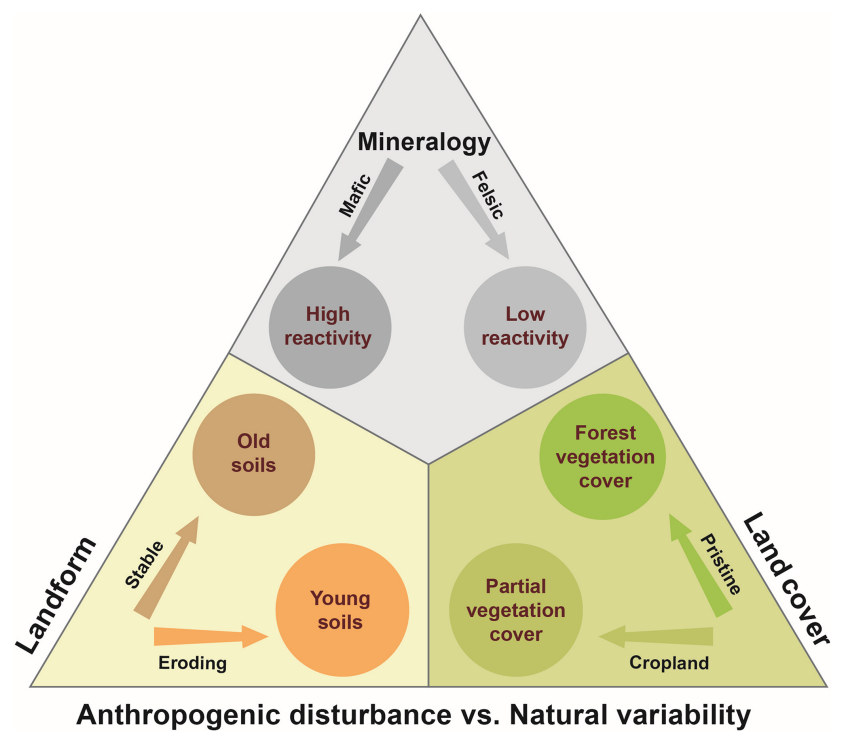

Figure 1. Factorial design of project TropSOC studying biogeochemical cycles in Central African tropical forest and agricultural landscapes in relation to mineralogy, landform, and land cover types.

and is being confronted with rapid land conversion and forest degradation (Hansen et al., 2013). The climate of the study region is classified as tropical humid with weak monsoonal dynamics (Köppen Af-Am) and mean annual temperatures (MAT) ranging between 15.3 and $19.3^{\circ} \mathrm{C}$ and mean annual precipitation (MAP) between 1498 and $1924 \mathrm{~mm}$ (Fick and Hijmans, 2017) with high potential erosivity (Fenta et al., 2017) (Fig. 2d).

As a part of the East African Rift mountain system, the active tectonism within the study region produced a hilly, patchy landscape with steep slopes up to $60 \%$ and soil parent material ranging from volcanic ashes to mafic and felsic magmatic rocks, as well as a sedimentary rocks of varying geochemistry and texture (Schlüter and Trauth, 2006) (Fig. 2a, b).

The study area is dominated by agricultural land use, with larger patches of protected, old-growth closed-canopy forest in highland areas (Fig. 2c). Typical crops planted for subsistence farming are rotations of cassava (Manihot esculenta), maize (Zea mays), and a variety of legumes and vegetables. The dominant vegetation in all studied forests of the region is characterized as tropical mountain forest (Verhegghen et al., 2012; van Breugel et al., 2015). Note that while forest vegetation is thought to be largely spared from direct disturbance by human activities, large mammal populations (i.e., African forest elephants, great apes) became extinct or largely reduced due to hunting during the 20th century resulting in a massive increase in understory. 


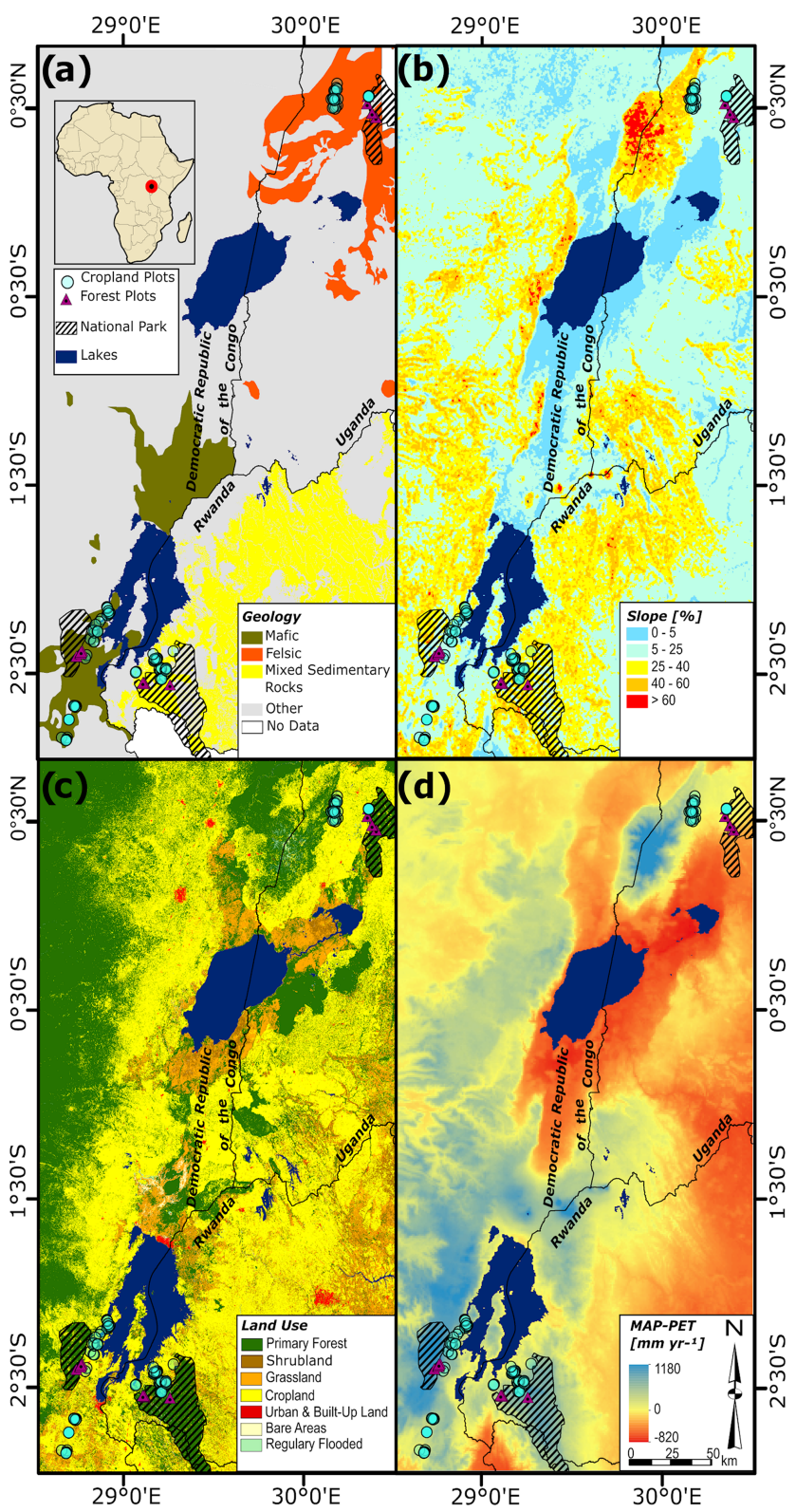

Figure 2. Overview of the study region with respect to major investigated factors: soil parent material geology and geochemical regions (a), slope steepness (b), land use (c), and climate (d) (data sources: Farr et al., 2007; Fick and Hijmans, 2017; Friedl et al., 2013; Dewitte et al., 2013; Dressée et al., 1949; Trabucco and Zomer et al., 2018; Verdooht and Van Ranst, 2003).

\subsection{Study area - geochemistry and soil types}

Within the study area three regions each representing a geochemically different parent material for soil formation were determined. The first region (Fig. 2a) is predominantly situated on mafic magmatic rocks, typically mafic alkali basalts (Schlüter and Trauth, 2006), resulting from extinct (Mount Kahuzi) and active (Mount Nyiragongo) volcanic activities between the cities of Bukavu and Goma, Kivu, DRC. The second region is situated on felsic magmatic and metamorphic rocks typically consisting of gneissic granites (Schlüter and Trauth, 2006) near the city of Fort Portal on the foothills of the Rwenzori Mountains, Uganda. The third region is situated on a mixture of sedimentary rocks of varying geochemistry consisting of alternate layers of quartz-rich sandstone, siltstone, and dark clay schists (Schlüter and Trauth, 2006) and spread across the western province of Rwanda in and around the district of Rusizi.

The dominant soil types of the study region are various forms of deeply weathered tropical soils (FAO, 2014). Potential ash deposition through the region's active volcanism occurs frequently, re-fertilizing soils to various degrees. Following World Reference Base (WRB) soil classification (IUSS, 2014), soils in the mafic region can be described as umbric, vetic, and geric Ferralsol and ferralic vetic Nitisol. Soils in the mixed sedimentary rock region and the felsic region can be described as geric and vetic Ferralsol. Soils in valley bottoms can locally show gleyic features, where the dominating soil types are variations of fluvic Gleysol.

Several striking differences in the elemental composition of the three parent materials can be noted. In the mafic region, bedrock is characterized by high iron $(\mathrm{Fe})$ and aluminum $(\mathrm{Al})$ content, as well as a comparably high content of rock-derived nutrients such as base cations and phosphorus (P). The felsic and sedimentary rock regions are characterized by lower contents of $\mathrm{Fe}$ and $\mathrm{Al}$, by lower rock-derived nutrient contents, and by higher Si content (Fig. 3). A specific feature of the sedimentary site is the presence of fossil organic $\mathrm{C}$ in the parent material of soils ranging between $1.29 \%$ and $4.03 \%$ C. Fossil organic $\mathrm{C}$ in these sediments is further characterized by a high $\mathrm{C}: \mathrm{N}$ ratio (mean \pm standard deviation: $153.9 \pm 68.5$ ), depleted in $\mathrm{N}$ and free of ${ }^{14} \mathrm{C}$ (due to the high age of sedimentary rock formation). The elemental composition of soils at a stable landscape position between the three regions retains the geochemical features of its parent material to some degree and illustrates the process of enrichment of metal oxy-hydroxides and the depletion of silica as a consequence of weathering. Generally, differences in the elemental concentrations between the three regions are less pronounced in soil (Fig. 4) compared to differences in parent material (Fig. 3). Remarkably, levels of rock-derived nutrients in soil, while overall depleted compared to the parent material, are comparably similar, potentially indicating biological mechanisms that protect these important nutrients in the plant-soil system against a general trend of leaching and depletion, typical for weathered, old, and nutrient-poor tropical soils (Grau et al., 2017 and references therein).

In summary, the study region provides a unique combination of (i) near-pristine forest and agricultural land, (ii) steep terrain and heavy tropical precipitation with high erosion potential, and (iii) geologically diverse parent material for soil formation. These factors make the study region ideal for identifying the importance of various controls on tropical soil biogeochemical cycles. 


\subsection{Overview of plots and sampling design}

Plots were established along geomorphic gradients in oldgrowth closed-canopy forest, as well as in cropland, in all three geochemical regions. Field campaigns to collect soil and plant samples at 136 forest and cropland plots along slope gradients (catena and stratified random approaches) and additionally within several cropped nearby micro-catchments were carried out between March 2018 and July 2020. A detailed description on data quantity and quality can be found in the metadata files accompanying the database and are briefly described in Sect. 4.1 of this publication. In order to cover potentially stable, eroding, and depositional landforms, topographic positions of plots ranged from plateaus (slope $<5 \%$ ), over two slope positions (slopes between $9 \%$ and $60 \%$ ) to valley positions (slopes $<5 \%$ ) (Table 1).

\subsection{Sampling design forest}

\subsubsection{Forest plot installation}

Sampling in forests followed a strict catena approach, and plots were established following an international, standardized protocol for tropical regions (Phillips et al., 2016). Within each geochemical region, three plots covered by oldgrowth closed-canopy tropical forest vegetation (forest that developed a complex structure characterized by large, living and dead trees) were established from February to June 2018 per topographic position as field replicates representing an area of $40 \mathrm{~m} \times 40 \mathrm{~m}$ per plot were established. Each plot was subdivided in four $20 \mathrm{~m} \times 20 \mathrm{~m}$ subplots, and a total of 36 forest plots were established this way (four topographic positions with three replicate plots each in three geochemical regions). Note that three plots in the mafic region had to be relocated due to safety reasons after the sampling period. For an overview of forest plot sampling design, see Fig. 5a.

\subsubsection{Sampling mineral and organic soil layers}

At the time of plot installation, four replicate soil cores per plot (one in each subplot) were taken in a depth-explicit way in $10 \mathrm{~cm}$ increments up to $1 \mathrm{~m}$ soil depth and combined as composites per plot. In addition, one soil profile pit was dug to a depth of $100 \mathrm{~cm}$ in the center of one of three replicate plots (Fig. 5) per topographic position in each geochemical region. These soil pits were dug and described according to FAO guidelines (FAO, 2006).

Leaf litter (L horizon) and partially decomposed organic material in $\mathrm{O}$ horizons were sampled at eight points along the border and in the center of each forest plot (Fig. 5a). At each sampling point, the thickness of the $\mathrm{L}$ and $\mathrm{O}$ horizon layer was measured with a ruler and then sampled within a $5 \mathrm{~cm} \times 5 \mathrm{~cm}$ square. When the litter layer was too thin (= no closed coverage of forest floor with litter), the sampling square was expanded to a $10 \mathrm{~cm} \times 10 \mathrm{~cm}$ to retrieve enough sample material. The nine samples of each layer per plot were combined to one composite sample.

All collected composite samples were kept cooled until being brought to the laboratory (usually within $48 \mathrm{~h}$ ). In the laboratory, samples were oven-dried at $40{ }^{\circ} \mathrm{C}$ for $48-96 \mathrm{~h}$ and then weighed (accuracy: $\pm 0.01 \mathrm{~g}$ ). Derived soil parameters are detailed in Sect. 2.7.

\subsubsection{Forest inventory and aboveground standing biomass}

In 2018, full inventories of the forest tree species and standing aboveground biomass (AGB) were conducted on all forest plots. The forest inventory followed an international, standardized protocol for tropical regions (Matthews et al., 2012). First, we identified, to species level, all living trees with a diameter at breast height (DBH; measured at $1.3 \mathrm{~m}$ above ground) greater than $10 \mathrm{~cm}$ in each plot. Second, these identified trees were classified into the following empirical DBH classes: 10-20, 20-30, 30-50, and $>50 \mathrm{~cm}$. Third, to estimate the AGB, we constructed stand-specific height diameter $(H-D)$ allometric relationships using a representative subset of the plot-specific trees (Méchain et al., 2017). For this, $20 \%$ of all measured, specific trees were selected for height measurement across the $\mathrm{DBH}$ range that was recorded per plot. Depending on the tree abundance of each DBH class, the heights of three to five individual trees were then measured using a hypsometer (Nikon Forestry Pro II laser rangefinder, Nikon, Japan). AGB for each individual tree was then estimated using the allometric equation as described by Chave et al. (2014) for moist tropical forests. To estimate wood density data, we used species averages from the DRYAD global wood density database (Zanne et al., 2009). To extrapolate this information for the entire plot for all our sites, we applied a stand-specific heightdiameter regression model, modelHD, available within the $\mathrm{R}$ package BIOMASS (Méchain et al., 2017). Finally, aboveground standing biomass carbon stock was estimated assuming that all samples standing biomass has a $50 \mathrm{wt} \%$ share of C (Chave et al., 2005). A re-census was carried out in 2020, in order to detect changes in aboveground standing biomass and to determine tree mortality. Tree mortality rate $(\lambda)$ at each plot was assessed following Lewis et al. (2004) using inventories conducted in 2018 and 2020. The tree mortality rate was calculated for all tree stems with $\mathrm{DBH}>10 \mathrm{~cm}$ in every plot.

\subsubsection{Canopy leaves}

To assess plant functional traits (leaf nitrogen, phosphorus, potassium, magnesium, and calcium content) of living canopy leaves (see Sect. 2.7), we sampled, at the beginning of the weak dry season (December-February), sun-exposed shoots from the outer canopy of selected tree species that collectively make up $80 \%$ of the standing basal area per plot 

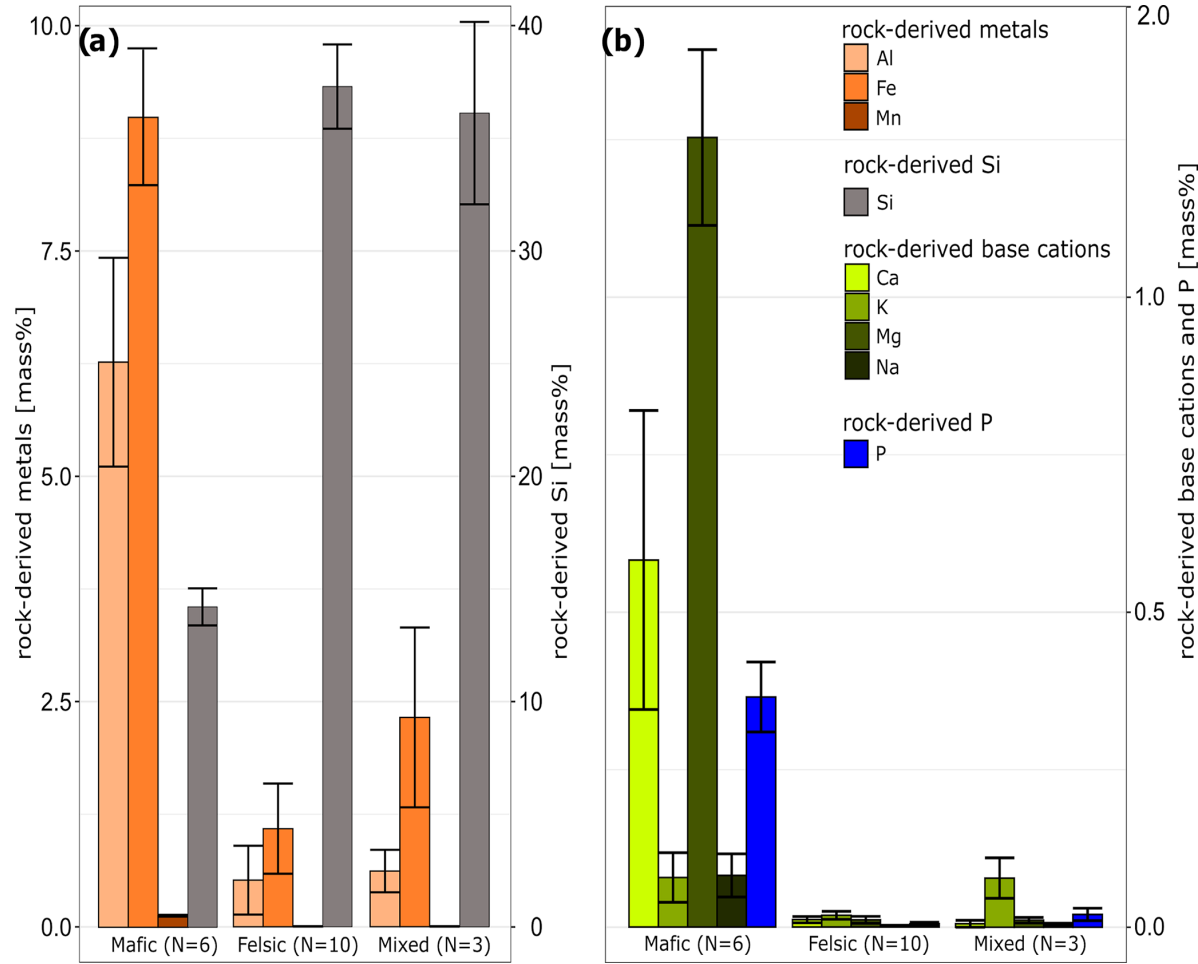

Figure 3. Chemical composition of unweathered rock samples representing the parent material for soil formation in three studied geochemical regions (mean \pm standard error). Panel (a) shows the distribution and concentration of rock-derived aluminum ( $\mathrm{Al})$, iron $(\mathrm{Fe})$, and manganese $(\mathrm{Mn})$ and total silica content $(\mathrm{Si})$. Panel (b) shows the distribution and concentration of rock-derived calcium (Ca), potassium $(\mathrm{K})$, magnesium $(\mathrm{Mg})$, sodium $(\mathrm{Na})$, and phosphorus $(\mathrm{P})$. Note the difference in scale on the $y$ axis between panels (a) and (b).

Table 1. Topographic information of TropSOC plots across different geochemical regions and land use. Slope and altitude are displayed as minimum and maximum values. Each topographic position per geochemical region contains the range between three and seven field replicate plots.

\begin{tabular}{|c|c|c|c|c|c|c|}
\hline \multirow[b]{3}{*}{ Topographic position } & \multicolumn{6}{|c|}{ Felsic region (Uganda) } \\
\hline & \multicolumn{3}{|c|}{ Forest plots } & \multicolumn{3}{|c|}{ Cropland plots } \\
\hline & Plateau & Sloping & Valley & Plateau & Sloping & Valley \\
\hline Slope $(\%)$ & $3-5$ & $9-55$ & 3 & $1-5$ & $7-50$ & $1-5$ \\
\hline \multirow[t]{3}{*}{ Altitude (m) a.s.1 } & 1304-1306 & $1271-1420$ & $1272-1277$ & $1507-1797$ & $1466-1830$ & $1587-1768$ \\
\hline & \multicolumn{6}{|c|}{ Mafic region (DRC) } \\
\hline & \multicolumn{3}{|c|}{ Forest plots } & \multicolumn{3}{|c|}{ Cropland plots } \\
\hline Topographic position & Plateau & Sloping & Valley & Plateau & Sloping & Valley \\
\hline Slope $(\%)$ & 3 & $11-60$ & $1-2$ & $0-5$ & $8-43$ & $0-3$ \\
\hline \multirow[t]{3}{*}{ Altitude (m) a.s.1 } & $2208-2227$ & $2188-2248$ & $2181-2310$ & $1477-1731$ & $1486-1774$ & $1505-1708$ \\
\hline & \multicolumn{6}{|c|}{ Mixed sedimentary region (Rwanda) } \\
\hline & \multicolumn{3}{|c|}{ Forest plots } & \multicolumn{3}{|c|}{ Cropland plots } \\
\hline Topographic position & Plateau & Sloping & Valley & Plateau & Sloping & Valley \\
\hline Slope $(\%)$ & 3 & $9-60$ & 1 & $3-5$ & $8-50$ & $2-5$ \\
\hline Altitude (m) a.s.l & 1908-1939 & $1891-2395$ & $1882-1889$ & $1719-1837$ & $1565-1952$ & $1556-1758$ \\
\hline
\end{tabular}



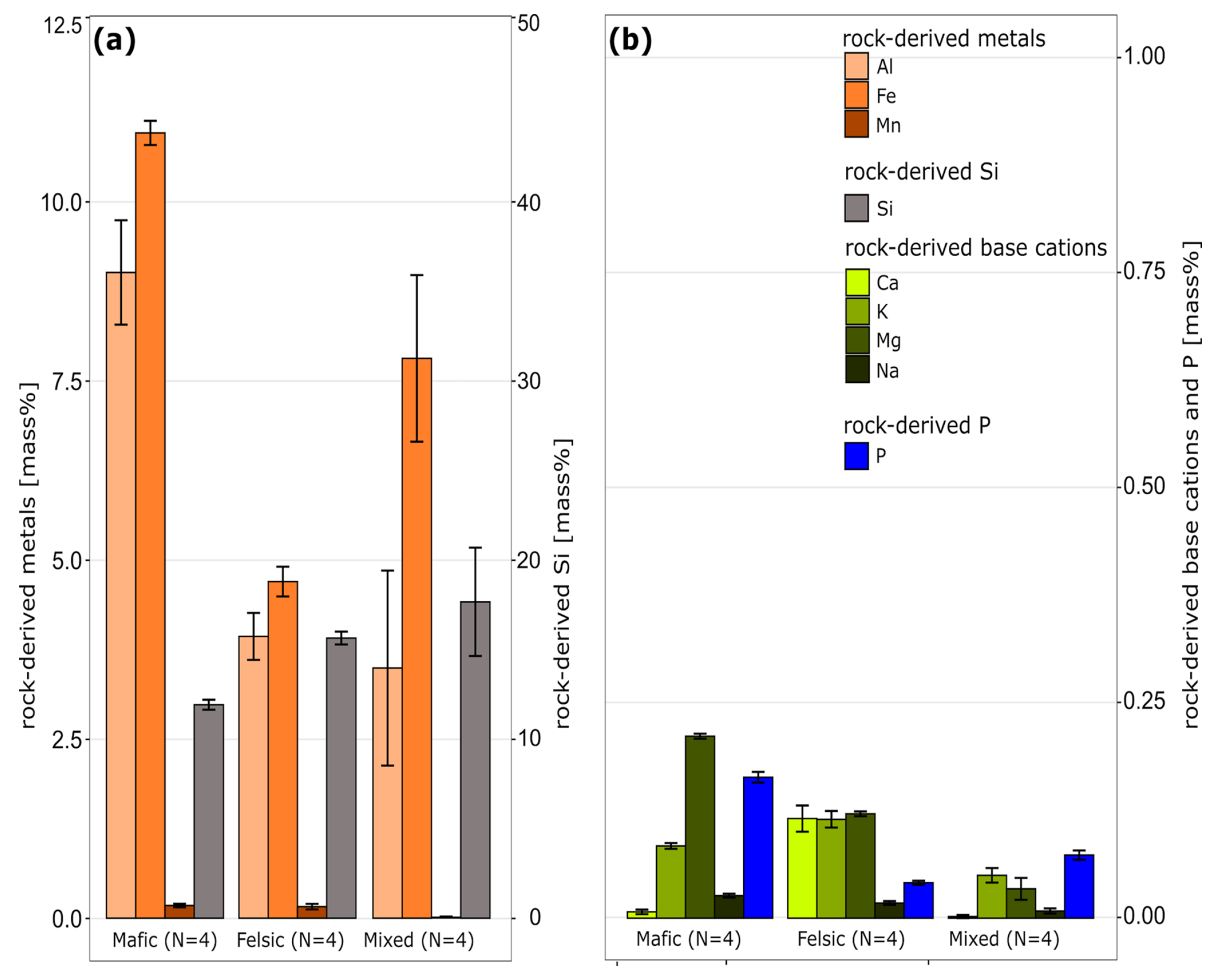

Figure 4. Soil chemical composition of subsoil in stable, old-growth closed-canopy forests (no erosion) in the three investigated geochemical regions (mean \pm standard error). The data illustrate the convergence of elemental concentrations between the three regions as a result of weathering and soil development. Abbreviations explained in Fig. 3. Note the difference in scale on the $y$ axis between panels (a) and (b).
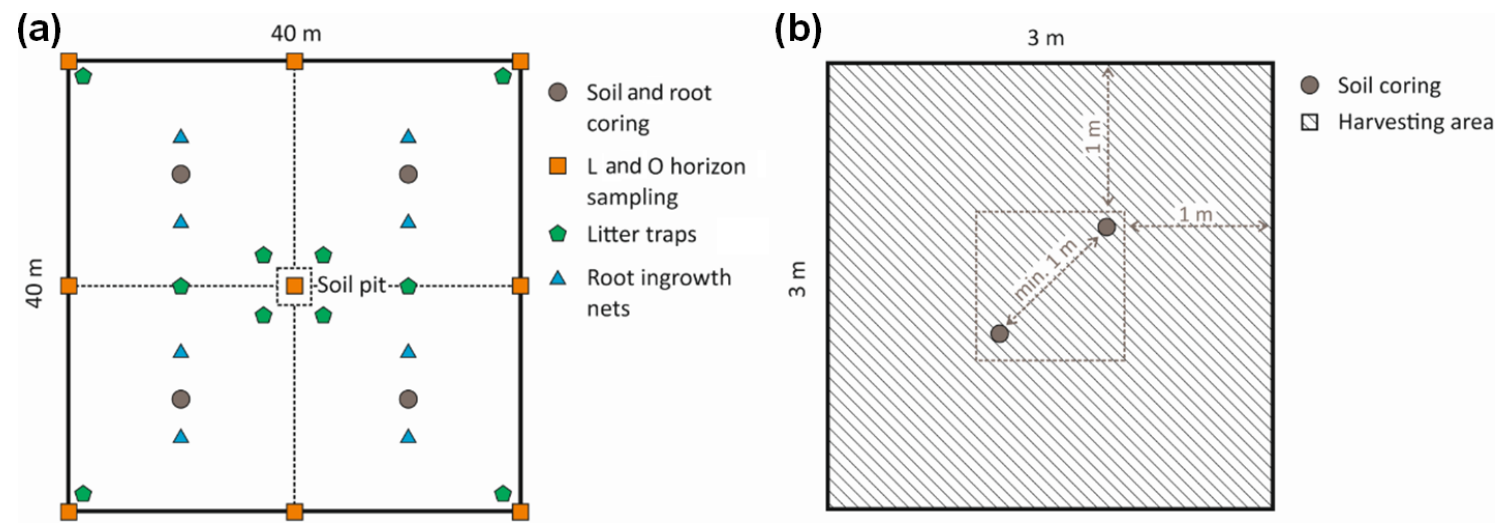

Figure 5. Overview of forest (a) and cropland (b) plot sampling design. Forest plots were subdivided into four $20 \mathrm{~m} \times 20 \mathrm{~m}$ subplots, and one soil profile pit was established per topographic position in each geochemical region for one of three replicate plots.

with the help of trained tree climbers and following a sampling protocol described in Pérez-Harguindeguy et al. (2016). For every tree species, we selected at least 3 individual trees, and a minimum of 5 and maximum of 17 trees per plot were sampled for mature, healthy-looking (= without signs of herbivory) individual canopy leaves. Where sampling of outer canopy leaves was physically not feasible, partially shaded leaves situated below the uppermost canopy were sampled.

\subsection{Sampling design cropland}

\subsubsection{Cropland plot installation}

Plots on cropland were established following a stratified random approach using the same slope classification and selection criteria as for forest sites. However, cropland plots belonging to the same geochemical region and topographic position were not connected along a hillslope catena. On cropland, only fields that were currently covered by cassava were sampled. Cassava fields were chosen since cassava is one of 
the most important food crops in the region and is harvested for both tubers and leaves. Rotations of cassava, maize, pulses, and vegetables are common throughout the area, and two harvests are possible per year. The main varieties of cassava on our sites were Mwabailon, Nabiombo, Mwamizinzi, Sawasawa (in eastern DRC), Bukalasa, Shayidire, Gitamisi, Amaduda (in Rwanda), Sambati, and Mubalaya (in Uganda). Only fields without soil protection measurements (i.e., terraced systems) were sampled. For an overview of forest plot sampling design, see Fig. 5 b.

\subsubsection{Soil sampling}

Soil sampling was carried out in the same way as for forest soils with the exception that only two cores were combined per plot taken within a $3 \mathrm{~m} \times 3 \mathrm{~m}$ area to create depth-explicit composite samples. A total of 100 cropland plots were sampled this way (Fig. 5) with 3-7 field replicate plots per topographic position (plateaus, slopes, valleys) in each geochemical region. No organic litter layers ( $\mathrm{L}$ and $\mathrm{O}$ horizons) were present in cropland, and no soil profile description was carried out. Derived soil parameters are detailed in Sect. 2.7.

\subsubsection{Biomass and crop yield}

As part of the regional stratified random sampling design for cropland plots (see cropland plot installation), biomass from different cassava varieties was collected for 65 plots out of the 100 sampled cropland plots. Biomass was sampled shortly before harvest, approximately at the time of the plant tuber's maximum development. The timing of harvest differed between 12 and 24 months after planting depending on the variety and season. Within each plot, a $3 \mathrm{~m} \times 3 \mathrm{~m}$ sampling area was chosen close to the center of each field, and all cassava plants in this area were counted and harvested. The biomass of all plants was separated into leaves, stems, and tubers. These parts were then weighed separately and individually at the time of sampling (i.e., in a field moist state).

\subsubsection{Land use history and management assessment}

Farmers were sent a questionnaire to collect information on the land use and management history of sampled fields following McCarthy et al. (2018). This questionnaire was completed for a corresponding total count of 87 out of the 100 sampled cropland plots.

\subsection{Monitoring design}

\subsubsection{Micrometeorological data}

Three weather stations (ATMOS 41, Meter, Germany) were installed in August 2018, one in each geochemical region of project TropSOC close to the investigated forest catenae (mafic: latitude $-2.324457^{\circ}$, longitude $28.740818^{\circ}$; felsic: latitude $0.561767^{\circ}$, longitude $30.356808^{\circ}$, mixed sedi- mentary rocks: latitude $-2.460503^{\circ}$, longitude $29.095251^{\circ}$ ). An additional weather station was installed in the mafic region near a cropland catchment (latitude $-2.583984^{\circ}$, longitude $28.715298^{\circ}$ ) which was selected for high-resolution erosion monitoring (see Wilken et al., 2021). Furthermore, a meteorological station in the city of Bukavu (latitude $-2.499979^{\circ}$, longitude $28.845009^{\circ}$ ) and one in Lukananda (latitude $-2.344073^{\circ}$, longitude $28.750937^{\circ}$ ) were put into operation. All stations collected data at a temporal resolution of $5 \mathrm{~min}$ on precipitation, air temperature, relative humidity, and air pressure. Additionally, global radiation and wind speed were measured at the Bukavu and Lukananda stations.

\subsubsection{Litterfall sampling}

Litterfall was assessed following a standardized protocol to measure tropical forest carbon allocation and cycling (Matthews et al., 2012). At each of our 36 forest soil sampled plots, 10 litter traps were installed and distributed evenly and systematically per plot. These had a diameter of $60 \mathrm{~cm}$ each and were installed at a height of $1.0 \mathrm{~m}$ above ground. Litter samples were collected every two weeks for the period between August 2018 and February 2020 and later aggregated to assess seasonal and annual variability in litter productivity and quality (see Sect. 2.4). Collected litter included all organic residues collected by the traps. Larger dead animals and woody material $>2 \mathrm{~cm}$ in diameter were discarded. After sampling, material from all 10 traps per plot was mixed to obtain a composite sample. These composite samples were taken to the laboratory the day of sampling, oven-dried at $70^{\circ} \mathrm{C}$ for $72 \mathrm{~h}$, and subsequently weighed (dry weight, accuracy: $\pm 0.01 \mathrm{~g})$. Data are provided as megagrams per hectare per day $\left(\mathrm{Mg} \mathrm{ha}^{-1} \mathrm{~d}^{-1}\right)$ per plot and as the sum of total litter production per plot, aggregated at the seasonal and annual level. The considered seasons were categorized based on the average precipitation for each period: weak dry season (December-February), strong wet season (MarchMay), strong dry season (June-August), and weak wet season (September-November).

\subsubsection{Belowground standing root biomass}

For all soil-sampled forest plots, standing root biomass and fine root production were assessed from September 2018 to December 2019. Sampling took place once per season within this period (one coring every 3 months), and a total of three rainy seasons and three dry seasons in 2018 and 2019 were covered. Each plot was divided into four equally sized subplots of $20 \mathrm{~m} \times 20 \mathrm{~m}$. Prior to deciding the root sampling strategy and size of depth intervals, root distribution was assessed using soil profiles that were dug in the plot centers for soil classification purposes. This assessment revealed that roots mostly dominated the organic horizons and the upper $50 \mathrm{~cm}$ of mineral soil (data not shown). 
Belowground standing root biomass was sampled using a soil core sampler (Vienna Scientific Instruments, Austria). Two cores were sampled per subplot in which undisturbed soil cores were divided into five depth layers: one organic soil layer (O horizon), and four mineral soil layers from 0 $10,10-20,20-30$, and $30-50 \mathrm{~cm}$. After transport to the laboratory, each sample was rinsed inside a $2 \mathrm{~mm}$ sieve; roots were separated into fine roots ( $\leq 2 \mathrm{~mm}$ diameter) and coarse roots ( $>2 \mathrm{~mm}$ diameter) using calipers. In addition, fine and coarse roots were separated into living and dead roots based on criteria such as color, root elasticity, and the degree of cohesion of cortex, periderm, and stele; i.a. roots were considered living when root steles were bright and resilient (Ostonen et al., 2005). The dry mass of isolated roots per plot was assessed after previously having dried the root samples at $70^{\circ} \mathrm{C}$ for $72 \mathrm{~h}$. Data are provided as milligrams per cubic centimeter $\left(\mathrm{mg} \mathrm{cm}^{-3}\right)$ per plot per sampling date and are also aggregated at the seasonal and annual level.

\subsubsection{Fine root net primary production}

Fine root net primary productivity was assessed using the ingrowth net method following Ohashi et al. (2016). Two net sheets (polyester mesh aperture size $2 \mathrm{~mm}, 10 \mathrm{~cm}$ wide, $20 \mathrm{~cm}$ high) were installed per subplot in a regular pattern with a distance of approximately $1 \mathrm{~m}$ between the two nets. Each net was vertically inserted in the top $20 \mathrm{~cm}$ of soil starting from the surface of the mineral layer. Nets were sampled every 3 months after installation and seasonally four times a year from September 2018 to December 2019. Data are provided as grams per square meter $\left(\mathrm{g} \mathrm{m}^{-2}\right)$ and grams per square meter per day $\left(\mathrm{g} \mathrm{m}^{-2} \mathrm{~d}^{-1}\right)$ of total fine root production per plot over a certain period of time, and they are also provided aggregated at the seasonal and annual level.

\subsection{Chemical and physical analyses}

A wide range of chemical and physical parameters were assessed for the sampled soil and plant material with the aim to characterize (i) indicators of soil redistribution, (ii) the degree of soil weathering, and (iii) the physical structure of soil, as well as (iv) soil fertility and (v) soil organic carbon characteristics, in order to link them to (vi) functional traits of the sampled biomass, (vii) biomass production, and (viii) land management. For a full overview of all assessed parameters including their assessment methods, please consult the metadata accompanying the database.

Among others, key measured parameters encompass the following:

Basic physical parameters

- Soil bulk density

- Soil texture

- Soil water holding capacity

\section{Basic chemical parameters}

- Soil pH (KCl)

- Soil potential cation exchange capacity and its base saturation

- Soil effective cation exchange capacity and its base saturation

- Main elemental composition of bulk soil (Al, Fe, Mn, $\mathrm{Si}, \mathrm{Ti}, \mathrm{Zr}, \mathrm{P})$ and the total reserve in base cations $(\mathrm{Ca}$, $\mathrm{Mg}, \mathrm{Na}, \mathrm{K}$ ) in rock parent material, soil, litter, and vegetation samples

- Pedogenic oxide concentration (Al, Fe, Mn)

Available nutrients

- Dissolvable soil organic nitrogen and carbon

- Plant available phosphorus in soil

\section{Organic matter characteristics}

- Total and organic carbon and nitrogen content in rock parent material, soil, litter, and vegetation samples

- Bulk soil radiocarbon signature

- $\mathrm{C}: \mathrm{N}$ ratio in soil, litter, and vegetation samples

- Soil carbon stabilization mechanisms

Microbial activity

- Heterotrophic soil respiration (including isotopic signature of respired gas)

- Microbial biomass during incubation

- Extracellular enzyme activity during incubation

\section{Soil redistribution}

$-239+240 \mathrm{Pu}$ activity

All of the parameters listed above have been measured in soil for three depth layers $(0-10,30-40,60-70 \mathrm{~cm})$ representing distinct sections of the soil profile. Physico-chemical key properties of the remainder of the soil samples in other soil layers have been assessed using mid-infrared spectroscopy and predicted following the workflow of Summerauer et al., 2021). An overview of chemical and physical key soil parameters is provided in Appendix Table A1. Note that all physico-chemical soil properties and the corresponding mid-infrared data are part of the central African spectral library (Summerauer et al., 2021), which minimizes the need for future traditional soil analyses. 


\subsection{Milestones reached}

Overall a total of approximately 2100 soil and rock samples were collected, of which about $10 \%-30 \%$ were used for yet more detailed analyses in different experiments by our group (see below). Additionally, 6000 above- and belowground biomass and litter samples were taken during several sampling and monitoring campaigns at forest and cropland sites. Several thousand near-infrared and mid-infrared (NIRMIR) spectra in the wavenumber range 600 to $7500 \mathrm{~cm}^{-1}$ (wavelength 1333.7-16666.7 $\mathrm{nm}$ ) were collected across the sampled plant and soil samples and were used to train calibration models for each property to predict spatially and depth-explicit soil parameters in relation to soil fertility, carbon stocks, and carbon stabilization using partial least square regressions following the workflow of Summerauer et al. (2021). Furthermore, since 2018, continuous monitoring has been carried out for the installed weather stations, and vegetation dynamics in tropical forests have been assessed from August 2018 until December 2019. Water and heat fluxes between soil and atmosphere are monitored using several weather stations and soil probes.

Analyses conducted on collected samples so far contributed to scientific advances realized through

- the creation of a data frame of reference samples for calibration used in the newly developed soil spectral library for central Africa (Summerauer et al., 2021)

- an investigation of the role of geochemistry and geomorphic position for soil organic matter stabilization mechanisms and patterns of soil organic carbon (SOC) stocks in tropical rainforests (Reichenbach et al., 2021)

- an investigation of the role of geochemistry and geomorphic position on the heterotrophic soil respiration (Bukombe et al., 2021)

- an assessment of the suitability and the application of radioisotope ${ }^{239+240} \mathrm{Pu}$ inventories for studying soil erosion processes in tropical forests and cropland (Wilken et al., 2021)

- soil fractionation and incubation experiments encompassing cropland soils along geomorphic and geochemical gradients (unpublished).

As part of this paper, the entirety of TropSOC's data is available as an open-access database with extensive metadata documenting experimental approaches, framing of the analyses, data quality, and methodology. An overview of all datasets presented in this database is given in Appendix Table A2.

In summary, TropSOC's first results demonstrate that even in deeply weathered tropical soils, parent material has a longlasting effect on soil chemistry that can influence and control microbial activity, the size of subsoil $\mathrm{C}$ stocks, and the turnover of $\mathrm{C}$ in soil. Soil parent material and the resulting soil chemistry need to be taken into account in understanding and predicting $\mathrm{C}$ stabilization and turnover in tropical forest soils. Given the investigated rates of erosion on cropland, our findings confirm the threat of large losses of organic matter leading to a sharp decline in soil fertility with little potential for soils to recover from nutrient losses naturally on decadal or centennial timescales. TropSOC highlights that considering feedbacks between geochemistry and topography to understand the development of soil fertility in the African Great Lakes regions can significantly improve our insights into the role of tropical soils to reach several key sustainable development goals, such as climate mitigation, zero hunger, and to help raise awareness of the need to maintain sufficient soil resources for future generations. Future work realized in project TropSOC based on the database will provide further insights into biomass and plant trait responses to soil geochemistry in forests, as well as cassava yield responses and SOC dynamics in cropland along the investigated geomorphic and geochemical gradients across the region.

\section{Structure of TropSOC project database (TropSOC v1.0)}

\subsection{Database hierarchy}

Datasets are given as tab-delimited .csv files. For each .csv file the metadata describing data structure and assessment methods are given in a .pdf file of the same name. Moreover, additional .pdf files for each main section of the database (basic information, forest, cropland, and microscale meteorology) are given, providing an overview of the structure within each section. Note that the "basic information" section of the database provides the linkages between individual data points, e.g., from soil analysis and the location and/or soil depths where these samples were acquired (for linkages, see also Fig. 6).

\subsection{Database infrastructure}

\subsubsection{Basic information}

The database comprises basic information of all plots and single point sampling positions where data were collected during project TropSOC. An overview of the structure of the database is presented in Appendix Table A2. The basic information of the database is structured in the following way.

Part 1. This is the location and basic background information for all plots and points where data were collected. Data can be found in file 11_plots_points.csv, with descriptions given in 11_plots_points.pdf.

Part 2. This includes the sample identifier for the database's internal connection between location of plots, points, and soil data from different soils depths, as well as vegetation data. Data are stored in 12_sample_identifier.csv, with descriptions given in 12_sample_identifier.pdf. 


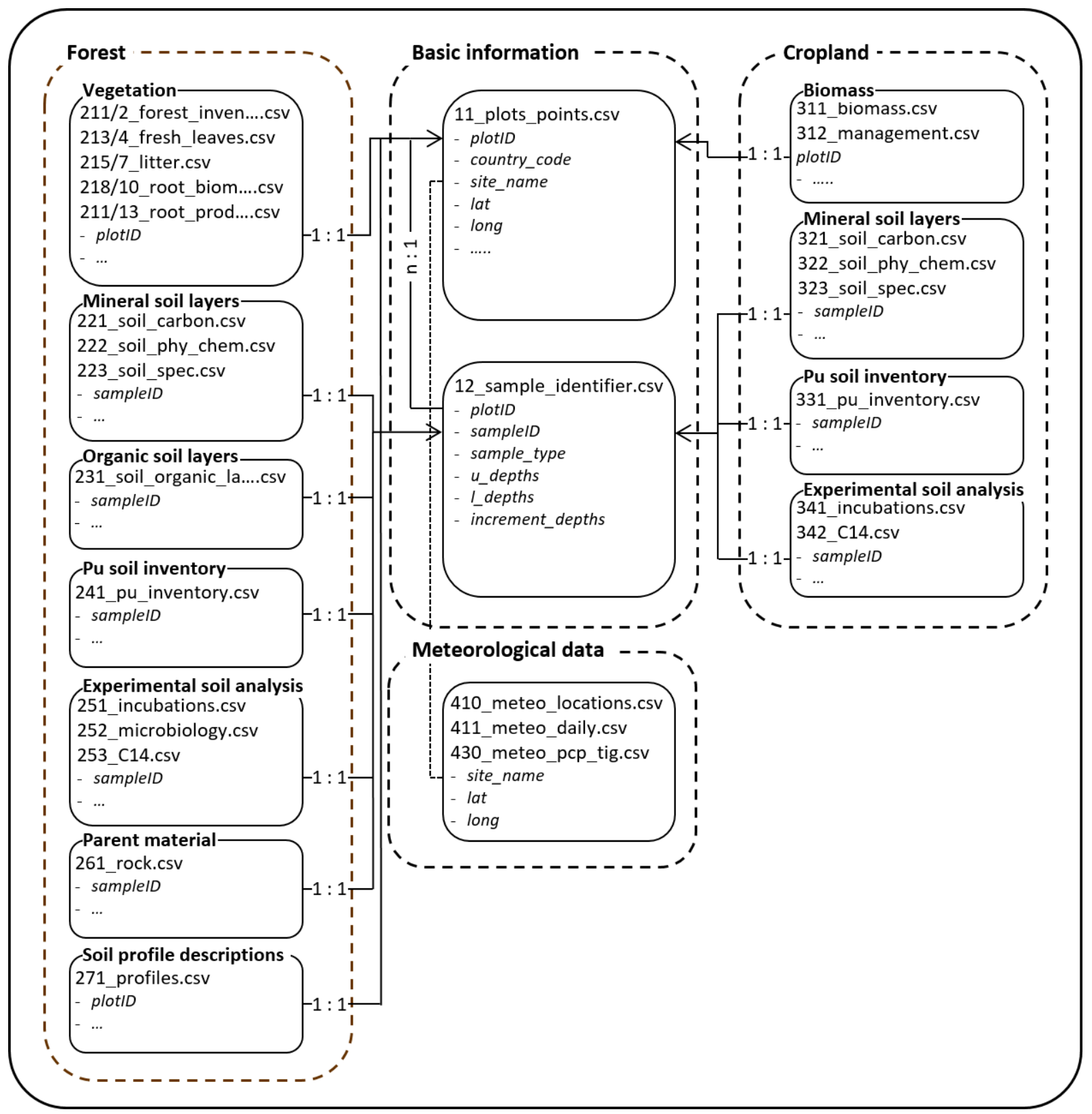

Figure 6. Overview of linkages between datasets in the TropSOC database v1.0. Note that for each data .csv file a .pdf file is given detailing the metadata of the respective data sheet.

The key element to link all data tables for which data were collected and analyzed is the plot ID and its derivative, the sample ID. This identifier allows us to link the results from sample analysis with the locations given in 11_plots_points.csv. This results in a n:1 connection between 12_sample_identifier.csv and 11_plots_points.csv. See metadata file 11_plots_points.pdf for an overview of the structure of the plots ID and 12_sample_identifier.pdf for an overview of the structure of the sample ID.

\subsubsection{Forest}

TropSOC's forest data consist of seven parts (Table A2 for overview) structured as paired .csv-.pdf files containing the data (.csv) and accompanying metadata (.pdf) describing parameters and methods. Additionally, an overview of all collected forest data is given in file 2_forest.pdf.

Part 1. Above- and belowground vegetation data were acquired in 2018, 2019, and 2020 at all forest plots, comprising 13 datasets (dataset files 2.1.1-2.1.13). 
Part 2. Mineral soil layer data were acquired in 2018 at all forest plots, comprising three data sets (dataset files 2.2.12.2.3).

Part 3. Organic soil layer data were acquired in 2018 at all forest plots, comprising one dataset (dataset file 2.3).

Part 4. The ${ }^{239+240} \mathrm{Pu}$ soil inventory was carried out in 2018. In contrast to parts 1 to 3 of the forest data, $\mathrm{Pu}$ data represent individual points and do not follow the plot concept in a strict manner (dataset file 2.4).

Part 5. Soil experiments were carried out from 2018 to 2020, comprising three datasets with results from laboratory soil incubation and fractionation experiments and additional data from soil sample analyses (dataset files 2.5.1-2.5.3).

Part 6. Parent material elemental composition was analyzed based on unweathered rock samples taken within plots or from nearby road cuts and mines surrounding the study sites (dataset file 2.6).

Part 7. Soil profile descriptions were done in soil pits at the center of plots following WRB-FAO soil description (dataset file 2.7).

\subsubsection{Cropland}

TropSOC's cropland data consist of the following seven parts (Table A2 for overview), structured as paired .csv.pdf files containing the data (.csv) and accompanying metadata (.pdf) describing parameters and methods. Additionally, an overview of all collected cropland data is given in file 3_cropland.pdf.

Part 1. Biomass and management data were acquired in 65 and 87 out of 100 sampled cropland plots respectively, comprising two datasets (dataset files 3.1.1-3.1.2).

Part 2. Data on mineral soil layers were acquired in 2018 for 100 cropland plots and comprising three datasets (dataset files 3.2.1-3.2.3).

Part 3. Pu soil inventory was carried out in 2018. In contrast to parts 1 and 2 of the cropland data, $\mathrm{Pu}$ data represent individual points and not plots and were sampled across several catchments (dataset file 3.3).

Part 4. For soil experiments, this part of the database comprises two datasets with results from laboratory soil incubation and fractionation experiments and additional data from soil sample analyses (dataset files 3.4.1-3.4.2).

\subsubsection{Meteorological data}

The meteorological data comprises four parts (Table A2 for overview), structured as paired .csv-.pdf files containing the data (.csv) and accompanying metadata (.pdf) describing parameters and methods.

Part 1: locations of meteorological stations. This includes coordinates, elevations, and contact addresses for the respective data (dataset file 4.1).

Part 2: daily meteorological data. Six meteorological stations recorded precipitation, air temperature, relative humid- ity, air pressure, solar radiation, and wind speed (dataset file 4.2).

Part 3: high-resolution 5 min triggered precipitation data. Precipitation was recorded at the time of tipping bucket tilt at a resolution of $5 \mathrm{~min}$ (dataset file 4.3).

\section{Database status}

\subsection{TropSOC v1.0}

The current version, v1.0, of TropSOC includes several thousand individual plant and soil samples collected across 136 sites, spanning cropland and forests in the East African Rift Valley system and a large variety of parameters. A total of 36 .csv data sheets are available that give all analyses completed for specific samples. Data sheets are structured according to the descriptions given in Sect. 3 and described and elaborated on in the accompanying metadata files. The current distribution of data points across the various levels of the database hierarchy is shown in Table 2. All individual data entries present in the database have passed quality control completed by experts who were involved in the creation of the data. When applicable, reports on the quality assessment of each parameter can be found in the metadata .pdf files accompanying the .csv files.

\subsection{Accessing TropSOC v1.0, asking questions, and reporting issues to its hosting platform $\mathrm{CBO}$}

Users may access the TropSOC database v1.0 and its supporting information through the Supplement provided as part of this submission. Version 1.0 of the database is also available through the data download section of the Congo Biogeochemistry Observatory (CBO) (https://www. congo-biogeochem.com/data, last access: 10 August 2021) and the PANGEA open-access environmental data repository. $\mathrm{CBO}$ is a consortium of multinational researchers from Africa, Europe, and the United States who study biogeochemical cycles and atmosphere-plant-soil interactions in tropical Africa with a focus on the Congo Basin and the African Great Lakes region (Doetterl et al., 2020). The dedication of young African researchers to understand and preserve the threatened natural resources of their home countries is paired with the resources of some of the most experienced and largest research groups focusing on African tropical forest and agroecosystems. Founded in 2018 by scientists of several African and European institutions and supported by multinational organization such as the Consultative Group for International Agricultural Research's International Institute of Tropical Agriculture (CGIAR-IITA) and the World Agroforestry Centre (CGIAR-ICRAF), CBO has become an important scientific network in tropical Africa for studying biogeochemistry in soils and sediments, creating synergies between key local institutions and international researchers which are crucial for the implementation 
Table 2. Overview of the current number of data points in TropSOC v1.0 on plant, soil, and meteorology and their affiliation to the hierarchical levels of forest and cropland. Numbers in tables refer to the number of data entries at the lowest available aggregation level $(=$ highest resolution of data). For details on parameters, see the corresponding metadata descriptions. Note that collected weather station data in the felsic (Uganda) and mixed sediment region (Rwanda) represent both cropland and forest, while separate stations were available for the two land cover classes in the mafic region (DRC). Abbreviations: $\mathrm{SOM}=$ soil organic matter.

\begin{tabular}{|c|c|c|c|c|c|c|}
\hline Plant-soil observations & Plots & $\begin{array}{r}\text { Bulk soil samples } \\
(0-100 \mathrm{~cm} \text { soil depth, } \\
10 \mathrm{~cm} \text { increments })\end{array}$ & $\begin{array}{r}\text { Bulk vegetation } \\
\text { samples (above/ } \\
\text { belowground) }\end{array}$ & $\begin{array}{l}\text { Incubated } \\
\text { soil layers }\end{array}$ & $\begin{array}{r}\text { SOM fractionated } \\
\text { soil layers }\end{array}$ & $\begin{array}{l}\text { Plots with } \\
\text { vegetation } \\
\text { assessments }\end{array}$ \\
\hline Cropland & 100 & 1190 & $132 / 66$ & 131 & 159 & 65 \\
\hline Total & 136 & 2106 & $1569 / 4400$ & 243 & 304 & 105 \\
\hline Mafic region (forest) & 1 & 674 & 858 & 860 & 860 & 644 \\
\hline Mafic region (cropland) & 3 & 1310 & 1310 & 1312 & 709 & 650 \\
\hline Mixed sediment region & 1 & 90 & 520 & 565 & 0 & 0 \\
\hline Total & 6 & 2615 & 3229 & 3278 & 1569 & 1294 \\
\hline
\end{tabular}

of research in remote and difficult to access environments. Research at CBO is funded and supported by German, Belgian, US, and Swiss research foundations and linked to research institutes at Ghent University, Augsburg University, Florida State University, ETH Zurich, the University of Louvain, TU Dresden, and the Max Planck Society.

Users are encouraged to provide feedback and corrections to existing data if problems are discovered by contacting CBO (contact@congo-biogeochem.com) or the corresponding author of this paper (sdoetterl@usys.ethz.ch). Corrections will be implemented in consecutive versions of the database that can be downloaded via the $\mathrm{CBO}$ site.

\subsection{Consecutive database versioning and archiving}

Updated versions of the database will be periodically released following either substantial changes or new peerreviewed publications using the dataset. The versions of these official releases are tracked using an associated version number, e.g., TropSOC v1.0, and so on. These official releases will be archived at ETH Zurich's Research Collection via ETH's Soil Resources Group (https://soilres. ethz.ch/, last access: 10 August 2021) and CBO's data storage (https://www.congo-biogeochem.com/data, last access: 10 August 2021) with a dataset DOI issued for each release via ETH Zurich so that users may revert back to the earlier version if so required. These archived releases will be maintained in perpetuity to facilitate reproduction of any analyses conducted using a past version of the database. When accessing the dataset and using it for one's own research, users commit to cite the original paper provided here in addition to the version number, DOI, and any description provided to future versions of the database (see Sect. 6 for details).

\section{Database governance and participation}

TropSOC is a community effort with multiple contributors operating at different levels (Fig. 7). Governance of TropSOC is required in order to ensure continuity of services and to plan for the future evolution of this data repository. Studying the rapid environmental changes to the African Tropics is a central research objective for the scientists of the Congo Biogeochemistry Observatory (CBO) making it the ideal body to govern future versions of TropSOC. The governance structure of TropSOC is briefly described in Fig. 7. While the TropSOC core team is responsible for the original version of the database, its maintenance, management, and archiving, scientists involved in the CBO oversee the establishment of cooperative agreements in the long term and act as a steering committee for modifications to TropSOC suggested by the research community. The main role of the steering committee is to determine the feasibility of major changes to TropSOC proposed by the community and to coordinate activities that would build upon TropSOC or continue similar research work within the framework of CBO. Although the structure of TropSOC is oriented around individual and research projects, the nature of scientific research is often more group-focused. For example, teams of researchers generally work together to seek out funding and to conduct research. Thus, in some cases a group or team of individuals may seek to utilize or modify TropSOC for their purposes. Such groups can petition the scientific steering committee (SCS) to be formally designated a CBO member group. Approved organizations should nominate a member to serve on the steering committee.

Interested researchers are also invited to contribute data to future versions of TropSOC in order to grow the database. Anyone can be a data contributor provided they agree to the 


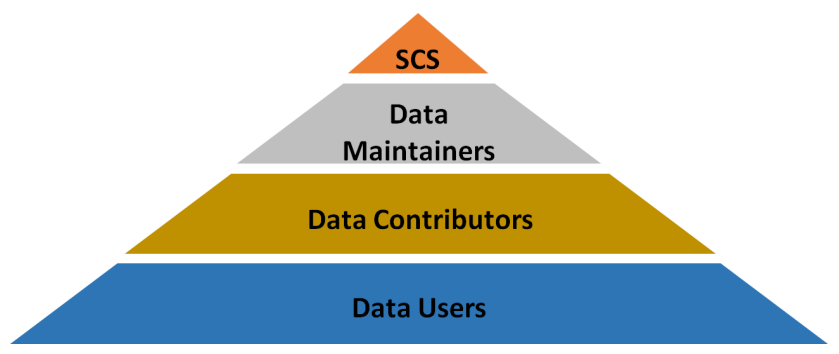

Figure 7. A simplified depiction of the TropSOC governance. The scientific steering committee (SCS) is responsible for approving major management decisions. The TropSOC core team as data maintainers are responsible for implementing broader changes together with new data contributors. All interested scientists are welcome to contribute data to future versions of the database or access the data for their own research.

terms of use and follow the proper steps for contributing data to TropSOC. If such suggestions arise, the $\mathrm{CBO}$ steering committee together with the TropSOC core team are responsible for approving the suggested changes and additions to the database. Upon approval, the TropSOC core team will coordinate with the new data contributors to implement the suggested data additions. In the case of organizations or individuals making larger changes or additions to TropSOC, a designated data maintainer from new contributor groups is required to coordinate the technical aspects of the implementation of changes together with the TropSOC core team. Within the pool of data contributors, individuals with significant experience working with TropSOC may be designated by either the steering committee or database maintainers as expert reviewers. These individuals are tasked to assist maintainers and oversee peer review and quality assessment of contributed new entries.

\section{Data availability}

All data presented in this study is part of the publication and added as a Supplement consisting of data tables (.csv) and accompanying metadata descriptions (.pdf files). In addition, the database and its metadata are archived and published in the open-access environmental and geoscience data repository GFZ Data Services, accessible at https://doi.org/10.5880/fidgeo.2021.009 (Doetterl et al., 2021). Additionally, the database is accessible via the website of the Congo Biogeochemistry Repository (https://www. congo-biogeochem.com/data, CBO, 2021). Updated versions of the database will be made available as version updates in both repositories. As detailed above, TropSOC is an open-source project that provides several ways for participation. Anyone may share the TropSOC dataset provided in accordance with the Creative Commons Attribution 4.0 International License (CC BY 4.0) and by citing the correspond- ing references of the original database description and future modifications under their separate DOI.

\section{Conclusions and outreach}

The TropSOC database is an attempt to gather the data used in individual studies in one place and in the same format to facilitate comparisons and synthesis activities. TropSOC is unique in that it includes measurements and monitoring data of bulk soil and vegetation responses in the African tropical context on carefully selected and comparable land use, geomorphic, and geochemical gradients on the landscape scale. Building on the data gathered along these gradients during several years of field activities and carrying out numerous lab experiments to investigate the impact of soil geochemistry and land degradation on biogeochemical cycles in tropical plant-soil systems, TropSOC is, to the best of our knowledge, the largest integrative project database on plant-microbial-soil systems in the Congo Basin to date. TropSOC's open-access database structure and participatory approach makes it a suitable tool for scientists to study experimentally defined soil disturbance and plant responses, as well as to test some of the assumptions behind modeling biogeochemical cycles in land surface models. Furthermore, we hope to encourage the community to increase the effectiveness of that investment and to use the TropSOC database as a repository to increase the impact of their own research results. As such, TropSOC is an interactive database that is open for contributions. In addition, TropSOC now manages one of the largest topically structured soil and plant sample archives for tropical eastern Africa with several thousand samples and more than three tons of plant and soil material stored at ETH Zurich. Subsamples of all the above are available upon request to interested researchers.

Finally, we hope that work based on the TropSOC database can help to provide answers on the role and magnitude of geochemistry, as well as soil mobilization, in controlling biological processes and fluxes of carbon and nutrients in the tropics in order to better constrain soil processes in models ranging from profile to global scales (Todd-Brown et al., 2013). Reducing the uncertainties associated with our understanding of tropical (agro-)ecosystems in diverse but rapidly changing landscapes is one of the most pressing issues for securing the future well-being of hundreds of millions of people and to constrain land loss in an area that is home to some of the last and most fragile populations of great apes in the wild. Further, elucidating the gravity of the consequences for soil functioning that can be observed in TropSOC's study area can contribute to reducing the large uncertainty associated with terrestrial biogeochemical processes in models. Finally, our hope is that studies based on TropSOC's data will also help to raise further awareness for the necessity of creating the socioeconomic fundamentals for sustainable land management in tropical Africa. 


\section{Appendix A}

Table A1. Basic chemical and physical soil parameters aggregated at land use and geochemical regions. Displayed are average values and standard deviations taken over 10 soil increments at $10 \mathrm{~cm}$ from $0-100 \mathrm{~cm}$ soil depth derived from NIR-MIR spectral data, calibrated on samples from three depth increments $(0-10,30-40$, and $60-70 \mathrm{~cm})$. See metadata files 223_soil_spec.pdf and 323_soil_spec.pdf for details. Abbreviations: $\mathrm{CEC}=$ potential cation exchange capacity; $\mathrm{ECEC}=$ effective cation exchange capacity; $\mathrm{Si}=\mathrm{silica} ; \mathrm{Al}=\mathrm{aluminum}$; $\mathrm{Fe}=$ iron; $\mathrm{Mn}=$ manganese $\mathrm{SOC}=$ soil organic carbon; $\mathrm{SON}=$ soil organic nitrogen; $\mathrm{P}=$ phosphorus; $\mathrm{TRB}=$ total reserve in base cations; $\mathrm{BD}=$ bulk density. All assessment methods are explained in the corresponding .pdf metadata files accompanying the database.

\begin{tabular}{|c|c|c|c|c|c|c|}
\hline \multirow{2}{*}{$\begin{array}{l}\text { Geochemical region } \\
\text { Land use }\end{array}$} & \multicolumn{2}{|c|}{ Mafic } & \multicolumn{2}{|c|}{ Felsic } & \multicolumn{2}{|c|}{ Mixed sedimentary rocks } \\
\hline & $\begin{array}{r}\text { Forest } \\
n=169\end{array}$ & $\begin{array}{r}\text { Cropland } \\
n=370\end{array}$ & $\begin{array}{r}\text { Forest } \\
n=201\end{array}$ & $\begin{array}{r}\text { Cropland } \\
n=239\end{array}$ & $\begin{array}{r}\text { Forest } \\
n=174\end{array}$ & $\begin{array}{r}\text { Cropland } \\
n=305\end{array}$ \\
\hline \multicolumn{7}{|l|}{ Soil chemistry } \\
\hline $\mathrm{pH}(\mathrm{KCl})$ & $3.92 \pm 0.45$ & $4.21 \pm 0.32$ & $4.96 \pm 0.64$ & $5.00 \pm 0.44$ & $3.48 \pm 0.35$ & $4.14 \pm 0.42$ \\
\hline $\mathrm{CEC}\left(\mathrm{me} 100 \mathrm{~g}^{-1}\right)$ & $34.14 \pm 4.89$ & $21.26 \pm 7.46$ & $15.24 \pm 5.37$ & $26.33 \pm 6.69$ & $14.71 \pm 11.50$ & $19.02 \pm 9.17$ \\
\hline Share of bases in CEC (\%) & $13.21 \pm 14.16$ & $13.90 \pm 10.04$ & $59.92 \pm 20.87$ & $52.72 \pm 12.75$ & $5.66 \pm 11.68$ & $18.58 \pm 17.65$ \\
\hline $\operatorname{ECEC}\left(\right.$ me $\left.100 \mathrm{~g}^{-1}\right)$ & $9.12 \pm 3.55$ & $4.90 \pm 3.00$ & $10.43 \pm 5.40$ & $13.74 \pm 3.93$ & $5.53 \pm 2.49$ & $6.49 \pm 4.63$ \\
\hline Share of bases in ECEC (\%) & $46.08 \pm 18.66$ & $48.69 \pm 15.67$ & $81.72 \pm 20.67$ & $91.74 \pm 16.45$ & $9.94 \pm 15.83$ & $41.36 \pm 23.13$ \\
\hline $\mathrm{Si}(\%)$ & $12.41 \pm 1.36$ & $11.88 \pm 2.18$ & $19.35 \pm 2.83$ & $16.35 \pm 1.88$ & $18.99 \pm 5.46$ & $15.59 \pm 1.84$ \\
\hline $\mathrm{Al}(\%)$ & $9.02 \pm 1.11$ & $6.37 \pm 2.39$ & $2.81 \pm 1.11$ & $4.08 \pm 1.29$ & $3.10 \pm 2.92$ & $3.20 \pm 1.97$ \\
\hline $\mathrm{Fe}(\%)$ & $10.32 \pm 1.67$ & $10.98 \pm 2.58$ & $3.50 \pm 1.84$ & $5.05 \pm 1.68$ & $5.65 \pm 3.54$ & $5.77 \pm 1.71$ \\
\hline $\operatorname{Mn}(\%)$ & $0.25 \pm 0.07$ & $0.19 \pm 0.10$ & $0.14 \pm 0.11$ & $0.26 \pm 0.10$ & $0.25 \pm 0.09$ & $0.08 \pm 0.12$ \\
\hline $\operatorname{SOC}(\%)$ & $2.79 \pm 1.55$ & $2.12 \pm 1.24$ & $1.17 \pm 1.25$ & $2.14 \pm 1.45$ & $2.87 \pm 1.82$ & $2.49 \pm 1.42$ \\
\hline $\operatorname{SON}(\%)$ & $0.28 \pm 0.14$ & $0.18 \pm 0.10$ & $0.12 \pm 0.12$ & $0.22 \pm 0.12$ & $0.15 \pm 0.14$ & $0.20 \pm 0.12$ \\
\hline SOC / SON (-) & $9.09 \pm 6.94$ & $15.2 \pm 7.89$ & $12.30 \pm 8.78$ & $11.67 \pm 14.07$ & $38.13 \pm 46.07$ & $20.52 \pm 9.07$ \\
\hline Total P (\%) & $0.20 \pm 0.07$ & $0.12 \pm 0.06$ & $0.12 \pm 0.06$ & $0.30 \pm 0.10$ & $0.07 \pm 0.07$ & $0.10 \pm 0.08$ \\
\hline TRB $(\%)$ & $0.56 \pm 0.22$ & $0.18 \pm 0.19$ & $0.60 \pm 0.27$ & $1.03 \pm 0.30$ & $0.09 \pm 0.17$ & $0.21 \pm 0.30$ \\
\hline \multicolumn{7}{|l|}{ Soil physics } \\
\hline $\mathrm{BD}\left(\mathrm{g} \mathrm{cm}^{-3}\right)$ & $1.20 \pm 0.14$ & $1.28 \pm 0.16$ & $1.64 \pm 0.16$ & $1.41 \pm 0.16$ & $1.43 \pm 0.34$ & $1.42 \pm 0.19$ \\
\hline Clay $(\%)$ & $54.79 \pm 11.79$ & $64.76 \pm 13.00$ & $41.45 \pm 11.44$ & $35.17 \pm 11.26$ & $39.60 \pm 14.77$ & $43.12 \pm 11.40$ \\
\hline Silt (\%) & $13.94 \pm 2.29$ & $11.01 \pm 3.28$ & $10.23 \pm 3.70$ & $14.42 \pm 3.76$ & $21.73 \pm 13.03$ & $14.45 \pm 5.20$ \\
\hline Sand (\%) & $31.39 \pm 10.20$ & $24.84 \pm 9.55$ & $51.08 \pm 10.52$ & $48.81 \pm 8.11$ & $39.10 \pm 18.69$ & $41.50 \pm 9.15$ \\
\hline
\end{tabular}


Table A2. Structure of the TropSOC database. For each topic a .pdf file is given that contains an overview of the available data on soil, vegetation, and weather collected for the investigated forest and cropland plots. Each dataset then comprises a data-containing .csv file and an additional metadata-containing .pdf file of the same name.

\begin{tabular}{|c|c|c|}
\hline & Introduction and structure of the database & 0_intro_structure.pdf \\
\hline 1 & Basic information & 1_basic_information.pdf \\
\hline 1.1 & $\begin{array}{l}\text { Location and basic background information for all plots } \\
\text { and points where data were collected }\end{array}$ & 11_plots_points.csv/pdf \\
\hline 1.2 & $\begin{array}{l}\text { Database internal connection between location of plots and points } \\
\text { and soil data from different soil depths }\end{array}$ & 12_sample_identifier.csv/pdf \\
\hline 2 & Forest & 2_forest.pdf \\
\hline 2.1 & Vegetation & \\
\hline 2.1 .1 & Forest inventory & 211_forest_invent.csv/pdf \\
\hline 2.1 .2 & Forest inventory aggregated & 212_forest_invent_agg.csv/pdf \\
\hline 2.1 .3 & Fresh leaves chemistry & 213 fresh_leaves.csv/pdf \\
\hline 2.1 .4 & Fresh leaves chemistry aggregated at species level & 214_fresh_leaves_agg.csv/pdf \\
\hline 2.1 .5 & Litter fall & 215_litter.csv/pdf \\
\hline 2.1 .6 & Litter fall aggregated to seasonal values & 216_litter_seasonal.csv/pdf \\
\hline 2.1 .7 & Litter fall aggregated to annual values & 217_litter_annual.csv/pdf \\
\hline 2.1 .8 & Root biomass & 218_root_biomass.csv/pdf \\
\hline 2.1 .9 & Root biomass aggregated to seasonal values & 219_root_biomass_seasonal.csv/pdf \\
\hline 2.1.10 & Root biomass aggregated to annual values & 2110_root_biomass_annual.csv/pdf \\
\hline 2.1.11 & Root productivity & 2111_root_prod.csv/pdf \\
\hline 2.1.12 & Root productivity aggregated to seasonal values & 2112_root_prod_seasonal.csv/pdf \\
\hline 2.1 .13 & Root productivity aggregated to annual values & 2113_root_prod_annual.csv/pdf \\
\hline 2.2 & Mineral soil layers & \\
\hline 2.2 .1 & Soil carbon and nitrogen including organic matter fractions & 221_soil_carbon.csv/pdf \\
\hline 2.2 .2 & Physicochemical soil properties from laboratory analyses & 222_soil_phy_chem.csv/pdf \\
\hline 2.2 .3 & Physicochemical soil properties from NIR-MIR spectroscopy & 223_soil_spec.csv/pdf \\
\hline 2.3 & Organic soil layers & 231_soil_organic_layer.csv/pdf \\
\hline 2.4 & Pu soil inventory & 241_pu_inventory.csv/pdf \\
\hline 2.5 & Soil experiments & \\
\hline 2.5.1 & Incubation experiments & 251_incubation.csv/pdf \\
\hline 2.5 .2 & Microbial biomass and enzyme experiments & 252_microbiology.csv/pdf \\
\hline 2.5 .3 & ${ }^{14} \mathrm{C}$ data from bulk soil and $\mathrm{CO}_{2}$ measurements & 253_c14.csv/pdf \\
\hline 2.6 & Parent material & 261_rocks.csv/pdf \\
\hline 2.7 & Soil profile descriptions & 271_profiles.csv/pdf \\
\hline 3 & Cropland & 3_cropland.pdf \\
\hline 3.1 & Biomass and management & \\
\hline 3.1 .1 & Biomass yield based on plot data & 311_biomass.csv/pdf \\
\hline 3.1 .2 & Land management data & 312_management.csv/pdf \\
\hline 3.2 & Mineral soil layers & \\
\hline 3.2 .1 & Soil carbon and nitrogen including organic matter fractions & 321_soil_carbon.csv/pdf \\
\hline 3.2 .2 & Physicochemical soil properties from laboratory methods & 322_soil_phy_chem.csv/pdf \\
\hline 3.2 .3 & Physicochemical soil properties from NIR-MIR spectroscopy & 323_soil_spec.csv/pdf \\
\hline 3.3 & $239+240 \mathrm{Pu}$ soil inventory & 331_pu_inventory.csv/pdf \\
\hline 3.4 & Soil experiments & \\
\hline 3.4 .1 & Incubation experiments & 341_incubation.csv/pdf \\
\hline 3.4 .2 & ${ }^{14} \mathrm{C}$ data from bulk soil and $\mathrm{CO}_{2}$ measurements & 342_c14.csv/pdf \\
\hline 4 & Meteorological data & 4_meteo.pdf \\
\hline 4.1 & Locations of meteorological stations & 410_meteo_locations.csv/pdf \\
\hline 4.2 & Daily meteorological data from six meteorological stations & 420_meteo_daily.csv/pdf \\
\hline 4.3 & High resolution 5 min triggered precipitation data & 430_meteo_pcp_tig.csv/pdf \\
\hline
\end{tabular}


Sample availability. Remaining soil and plant samples are logged and barcoded at the Department of Environmental Science at ETH Zurich, Switzerland. As long as idle sample mass remains available, samples for independent research and to stimulate collaboration with the $\mathrm{CBO}$ network and the TropSOC project group are available upon request. The authors cannot guarantee that they can revisit the study sites in order to provide additional sample material in future campaigns. Samples will be given to researchers free of charge. Sample preparation and transport are subject to a handling fee.

Supplement. The supplement related to this article is available online at: https://doi.org/10.5194/essd-13-4133-2021-supplement.

Author contributions. SD functioned as the project leader. SD and $\mathrm{PF}$ were lead coordinators for compiling the database, were responsible for data analysis, and designed the metadata. BB, MC, LK, DM, MR, LS, and FW collected and created datasets and also analyzed these data before their inclusion into the database. RKA, FB, MC, CB, AM, MM, JM, SMM, LN, AS, RU, and CV were technical contributors and participated via data collection. GB, MB, PB, $\mathrm{GC}, \mathrm{LNC}, \mathrm{AH}, \mathrm{KK}, \mathrm{BBM}, \mathrm{BR}, \mathrm{JS}, \mathrm{BV}, \mathrm{KVO}$, and $\mathrm{KV}$ were conceptual contributors and participated in the design of the study, as well as by giving advice and feedback during the campaign. SD and PF wrote the paper. All authors supported data analysis and gave feedback during the writing process.

Competing interests. The authors declare that they have no conflict of interest.

Disclaimer. Publisher's note: Copernicus Publications remains neutral with regard to jurisdictional claims in published maps and institutional affiliations.

Acknowledgements. This work is part of the DFG funded Emmy Noether Junior Research Group "Tropical soil organic carbon dynamics along erosional disturbance gradients in relation to soil geochemistry and land use" (TropSOC). Micrometeorological data from three of our weather stations (Bukavu, Lukananda, Bugulumiza) were made available and are administered by the Trans-African Hydro-Meteorological Observatory (TAHMO). The authors would like to thank in particular the following collaborating institutions for the support given to our scientists and this project: International Institute of Tropical Agriculture (CGIAR-IITA), Catholic University of Bukavu (UCB), Mountain of the Moon University (MMU), Kyaninga Forest Foundation (KFF), ETH Zurich, and the Max Planck Institute for Biogeochemistry in Jena. Special thanks goes to the many student assistants for their important work in the laboratory and all guards, sentinels, and field work helpers making the sampling campaign possible under difficult conditions. Lastly, we thank the editors of ESSD as well as the reviewers Yao Zhang and Rose Abramoff for their valuable insights and comments during the review process.

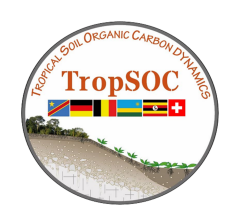

Financial support. This research has been supported by the Deutsche Forschungsgemeinschaft (grant no. 387472333).

Review statement. This paper was edited by Jocelyn Lavallee and reviewed by Yao Zhang and Rose Abramoff.

\section{References}

Alcántara, V., Don, A., Vesterdal, L., Well, R., and Nieder R.: Stability of buried carbon in deep-ploughed forest and cropland soils - implications for carbon stocks, Sci. Rep.-UK, 7, 5511, https://doi.org/10.1038/s41598-017-05501-y, 2017.

Amundson, R., Berhe, A. A., Hopmans, J. W., Olson, C., Sztein, A. E., and Sparks, D.L.: Soil and human security in the 21st century, Science, 348, 1261071, https://doi.org/10.1126/science.1261071, 2015.

Bauters, M., Moonen, P., Summerauer, L., Doetterl, S., Wasner, D., Griepentrog, M., Mumbanza, F. M., Kearsley, E., Ewango, C., Boyemba, F., Six, J., Muys, B., Verbist, B., Boeckx, P., and Verheyen, K.: Soil Nutrient Depletion and Tree Functional Composition Shift Following Repeated Clearing in Secondary Forests of the Congo Basin, Ecosystems, https://doi.org/10.1007/s10021020-00593-6, 2021.

Berhe, A. A., Harden, J. W., Torn, M. S., Kleber, M., Burton, S. D., and Harte, J.: Persistence of soil organic matter in eroding versus depositional landform positions, J. Geophys. Res.-Biogeo., 117, 1-16, https://doi.org/10.1029/2011JG001790, 2012.

Bukombe, B., Fiener, P., Hoyt, A. M., and Doetterl, S.: Controls on heterotrophic soil respiration and carbon cycling in geochemically distinct African tropical forest soils, SOIL Discuss. [preprint], https://doi.org/10.5194/soil-2020-96, in review, 2021.

Carreño-Rocabado, G., Claros-Peña, M., Bongers, F., Díaz, Quetier, F., Chuviña, J., and Poorter, L.: Land-use intensification effects on functional properties in tropical plant communities, Ecol. Appl., 26, 174-189, https://doi.org/10.1890/14-0340, 2016.

CBO - The Congo Biogeochemistry Observatory, https://www. congo-biogeochem.com/data, last access: 19 August 2021.

Chave J., Andalo, C. , Brown, S., Cairns, M. A. , Chambers, J. Q., Eamus, D., Fölster, H., Fromard, F., Higuchi, N., Kira, T., Lescure, J. P., Nelson, B. W., Ogawa, H., Puig, H., Riéra, B., and Yamakura, T. :Tree allometry and improved estimation of carbon stocks and balance in tropical forests, Oecologia, 145, 87-99, https://doi.org/10.1007/s00442-005-0100-x, 2005.

Chave, J., Rejou-Mechain, M., Burquez, A., Chidumayo, E., Colgan, M., Delitti, W., Eid, T., Duque, A., Fearnside, P., Goodman, R., Henry, M., Martínez-Yrízar, A., Mugasha, W., Muller-Landau, H., Mencuccini, M., Nelson, B., Ngomanda, A., Nogueira, E., Ortiz-Malavassi, E., Pélissier, R., Ploton, P., Ryan, C., Saldarriaga, J., and Vieilledent, G.: 
Improved allometric models to estimate the aboveground biomass of tropical trees, Glob. Change Biol., 20, 3177-3190, https://doi.org/10.1111/gcb.12629, 2014.

Curtis, P. G., Slay, C. M., Harris, N. L., Tyukavina, A., and Hansen, M. C.: Classifying drivers of global forest loss, Science, 361, 1108-1111, https://doi.org/10.1126/science.aau3445, 2018.

Dewitte, O., Jones, A., Spaargaren, O., Breuning-Madsen, H., Brossard, M., Dampha, A., Deckers, J., Gallali, T., Hallett, S., Jones, R., Kilasara, M., Le Roux, P., Michéli, E., Montanarella, L., Thiombiano, L., Van Ranst, E., Yemefack, M., and Zougmore, R.: Harmonisation of the soil map of Africa at the continental scale, Geoderma, 211-212, 138-153, https://doi.org/10.1016/j.geoderma.2013.07.007, 2013.

Doetterl, S., Six, J., Van Wesemael, B., and Van Oost, K.: Carbon cycling in eroding landscapes: Geomorphic controls on soil organic C pool composition and C stabilization, Glob. Change Biol., 18, 2218-2232, https://doi.org/10.1111/j.13652486.2012.02680.x, 2012.

Doetterl, S., Kearsley, E., Bauters, M., Hufkens, K., Lisingo, J., Baert, G., Verbeeck, H., and Boeckx, P.: Aboveground vs. belowground carbon stocks in African tropical lowland rainforest: Drivers and implications, PLoS One, 10, 1-14, https://doi.org/10.1371/journal.pone.0143209, 2015.

Doetterl, S., Berhe, A.A., Nadeu, E., Wang, Z., Sommer, M., and Fiener, P.: Erosion, deposition and soil carbon: a review of process-level controls, experimental tools and models to address C cycling in dynamic landscapes, Earth Sci. Rev., 154, 102-122, https://doi.org/10.1016/j.earscirev.2015.12.005, 2016.

Doetterl, S., Drake, T., Bauters, M., Van Oost, K., Barthel, M., and Hoyt, A.: Environmental research in the heart of Africa: The Congo biogeochemistry Observatory: The role of the changing Tropics for future global carbon dynamics, Editoria, Open Access Government, 25, 328-329, 2020.

Doetterl, S., Bukombe, B., Cooper, M., Kidinda, L., Muhindo, D., Reichenbach, M., Stegmann, A., Summerauer, L., Wilken, F., and Fiener, P.: TropSOC Database, Version 1.0, GFZ Data Services, https://doi.org/10.5880/fidgeo.2021.009, 2021.

Dressée P. L. C. and Lepersonne, J.: Carte Géologique 1.5000000 , Institut Royal Colonial Belge Commission cen-trale de látlas general du Congo Belge et du Ruanda-Urundi, Index No. 31, 1949.

Du, E., Terrer, C., Pellegrini, A., Ahlstrom, A., van Lissa, C. J., Zhao, X., Xia, N., and Jackson, R. B.: Global patterns of terrestrial nitrogen and phosphorus limitation, Nat. Geosci., 13, 221226, https://doi.org/10.1038/s41561-019-0530-4, 2020.

Dumbaugh, M., Bapolisi, W., Bisimwa, G., Mwamini, MC., Mommers, P., and Merten, S.: Navigatin fertility, reproduction and modern contraception in the fragile context of South Kivu, Democratic Republic of Congo: "Les enfants son tune richesse", Cult. Health Sex., 21, 323-337, https://doi.org/10.1080/13691058.2018.1470255, 2018.

Ewel, J. J., Mazzarino, M. J., and Berish, C. W.: Tropical Soil Fertility Changes Under Monocultures and Successional Communities of Different Structure, Ecol. Appl., 1, 289-302, https://doi.org/10.2307/1941758, 1991.

FAO: Guidelines for soil description, 4th edition, FAO, Rome, available at: http://www.fao.org/3/a-a0541e.pdf (last access: 1 December 2020), 2006.
FAO: World references base for soil resources 2014, International soil classification system for naming soils and creating legends for soil maps, Food and Agriculture Organization of the United Nations, Rome, Italy, 203 pp., 2014 (updated 2015).

Farr, T. G., Rosen, P. A., Caro, E., Crippen, R., Duren, R., Hensley, S., Kobrick, M., Paller, M., Rodriguez, E., Roth, L., Seal, D., Shaffer, S., Shimada, J., Umland, J., Werner, M., Oskin, M., Burbank, D., and Alsdorf, D. E.: The shuttle radar topography mission, Rev. Geophys., 45, RG2004, https://doi.org/10.1029/2005RG000183, 2007.

Fenta, A. A., Yasuda, H., Shimizu, K., Haregeweyn, N., Kawai, T., Sultan, D., Ebabu, K., and Belay, A.S.: Spatial distribution and temporal trends of rainfall and erosivity in the Eastern Africa region, Hydrol. Process., 31, 4555-4567, https://doi.org/10.1002/hyp.11378, 2017.

Fick, S. E. and Hijmans, R. J.: WorldClim 2: new 1-km spatial resolution climate surfaces for global land areas, Int. J. Climatol., 37, 4302-4315, https://doi.org/10.1002/joc.5086, 2017.

Friedl, M. A., Sulla-Menashe, D., Tan, B., Schneider, A., Ramankutty, N., Sibley, A., and Huang, X.: MODIS Collection 5 global land cover: Algorithm refinements and characterization of new datasets, Remote Sens. Environ., 114, 168-182, 2013.

Gerland, P., Raftery, A. E., Ševcíková, H., Li, N., Gu, D., Spoorenberg, T., Alkema, L., Fosdick, B. K., Chunn, J., Lalic, N., Bay, G., Buettner, T., Heilig, G. K., and Wilmoth, J.: World Population Stabilization Unlikely This Century, Science, 346, 234-237, https://doi.org/10.1126/science.1257469, 2014.

Grau, O., Peñuelas, J., Ferry, B., Freycon, V., Blanc, L., Desprez, M., Baraloto, C., Chave, J., Descroix, L., Doudain, A., Guitet, S., Janssens, I.A., Sardans, J., and Hérault, B.: Nutrient-cycling mechanisms other than the direct absorption from soil may control forest structure and dynamics in poor Amazonian soils, Sci. Rep.-UK, 7, 45017, https://doi.org/10.1038/srep45017, 2017.

Hahm, W. J., Riebe, C. S., Lukens, C. E., and Araki, S.: Bedrock composition regulates mountain ecosystems and landscape evolution, P. Natl. Acad. Sci. USA, 111, 3338-3343, https://doi.org/10.1073/pnas.1315667111, 2014.

Hansen, M. C., Potapov, P. V., Moore, R., Hancher, M., Turubanova, S. A., Tyukavina, A., Thau, D., Stehman, S. V., Goetz, S. J., Loveland, T. R., Kommareddy, A., Egorov, A., Chinin, L., Justice, C. O., and Townshends, J. R. G.: High-Resolution Global Maps of 21st-Century Forest Cover Change, Science, 342, 850 853, https://doi.org/10.1126/science.1244693, 2013.

Hattori, D., Kenzo, T., Shirahama, T., Harada, Y., Kendawang, J. J., Ninomiya, I., and Sakurai, K.: Degradation of soil nutrients and slow recovery of biomass following shifting cultivation in the heath forests of Sarawak, Malaysia, Forest Ecol. Manag., 432, 467-477, https://doi.org/10.1016/j.foreco.2018.09.051, 2019

Heinrich, V., Dalagnol, R., Cassol, H., Rosan, T., Torres de Almeida, C., Silva Junior, C. H. L., Campanharo, W., House, J., Sitch, S., Hales, T., Adami, M., Anderson, L., and Aragão, L.: Large carbon sink potential of Amazonian Secondary Forests to mitigate climate change, Europe PMC [preprint], https://doi.org/10.21203/rs.3.rs-71626/v1, 2020.

Heri-Kazi Bisimwa, A. and Bielders, C.: Dégradation des terres cultivées au Sud-Kivu, R.D. Congo: perceptions paysannes et caractéristiques des exploitations agricoles, Biotechnol. Agron. Soc., 200, 99-116, 2020. 
Hobley, E. U. and Wilson, B.: The depth distribution of organic carbon in the soils of eastern Australia, Ecosphere, 7, e01214, https://doi.org/10.1002/ecs2.1214, 2016.

International Union of Soil Sciences (IUSS) Working Group WRB: World reference base for soil resources 2014, World Soil Resources Reports No. 106, FAO, Rome, 2014 (updated 2015).

Jobbágy, E. and Jackson, R. B.: The Vertical Distribution of Soil Organic Carbon and Its Relation to Climate and Vegetation, Ecol. Appl., 10, 423-436, https://doi.org/10.1890/10510761(2000)010[0423:TVDOSO]2.0.CO;2, 2000.

Juo, A. S. R. and Franzluebbers, K.: Tropical Soils. Properties and Management for Sustainable Agriculture, Oxford University Press, New York, 2003.

Karamage, F., Shao, H., Chen, X., Ndayisaba, F., Nahayo, L., Kayiranga, A., Omifolaji, J. K., Liu, T., and Zhang, C.: Deforestation Effects on Soil Erosion in the Lake Kivu Basin, D.R. CongoRwanda, Forests, 7, 281, https://doi.org/10.3390/f7110281, 2016.

Kleinman, P., Bryant, R. B., and Pimentel, D.: Assessing ecological sustainability of slash-and-burn agriculture through soil fertility indicators, Agron. J., 88, 122-127, https://doi.org/10.2134/agronj1996.00021962008800020002x, 1996.

Kujirakqinja, D., Shamavu, P., Hammill, A., Crawford, A., Bamba, A., and Plumptre, A.J.: Healing the Rift: Peacebuilding in and around protected areas in the Democratic Republic of Congo's Albertine Rift, unpublished Report to USAID, IISD, WCS, 2010.

Lawrence, D., Radel, C., Tully, Schmook, B., and Schneider, L.: Untangling a Decline in Tropical Forest Resilience: Constraints on the Sustainability of Shifting Cultivation across the Globe, Biotropica, 42, 21-30, https://doi.org/10.1111/j.17447429.2009.00599.x, 2010.

Lewis, S. L., Phyllips, O. L., Sheil, D., Vinceti, B., Baker, T. R., Brown, S., Graham, A. W., Higuchi, N., Hilbert, D. W., Laurance, W. F., Lejoly, J., Malhi Y., Monteagudo, A., Vargas, P. N., Sonké, B., Supardi, N. M. N., Terborgh, J. W., and Martínez, R. V.: Tropical forest tree mortality, recruitment and turnover rates: calculation, interpretation and comparison when census intervals vary, J. Ecol., 92, 929-944, https://doi.org/10.1111/j.00220477.2004.00923.x, 2004.

Losos, E. and Leigh, E. G.: Tropical Forest Diversity and Dynamism, University of Chicago Press, Chicago, Illinois, United States, 688 pp., 2004.

Matthews, T. R., Metcalfe, D., Malhi, Y., Phillips, O., Huasco, H. W., Riutta, T., Ruiz Jaén, M., Girardin, C., Urrutia, R., Butt, N., Cain, R., Menor, O., and colleagues from the RAINFOR and GEM networks: Measuring tropical forest carbon allocation and cycling: a RAINFOR-GEM field manual for intensive census plots (v2.2), Manual, Global Ecosystems Monitoring network, 104 pp., available at: http://gem.tropicalforests.ox.ac.uk/ (last access: 1 October 2020), 2012.

McCarthy, J. S., Ott, K., Ridolfo H., McGovern, P., Sirkis, R., and Moore, D.: Combining Multiple Methods in Establishment Questionnaire Testing: The 2017 Census of Agriculture Testing Bento Box, J. Off. Stat., 34, 341-364, https://doi.org/10.2478/JOS-2018-0016, 2018.

Méchain, M., Ariane, T., Piponiot, C., Chave, J., and Hérault, B.: Biomass: An R Package for estimating above-ground biomass and its uncertainty in tropical forests, Methods Ecol. Evol., 8, 1163-1167, https://doi.org/10.1111/2041-210X.12753, 2017.

Mohr, E. C. J. and van Baren, F. A.: Tropical Soils: A Critical Study of Soil Genesis as Related to Climate, Rock and Vegetation, Interscience Publishers, The Hague, edited by: Van Hoeve, W., 498 pp., 1954.

Mohr, E. C. J., van Baren, F. A., and van Schuylenborgh, J.: Tropical Soils: a comprehensive study on their genesis, Mouton-Ichtiar Baru-Van Hoeve, The Hague, 490 pp., 1972.

Nadeu, E., Gobin, A., Fiener, P., Van Wesemael, B., and Van Oost, K.: Modelling the impact of agricultural management on soil carbon stocks at the regional scale: the role of lateral fluxes, Glob. Change Biol., 21, 3181-3192, https://doi.org/10.1111/gcb.12889, 2015.

Ohashi, M., Nakano, A., Hirano, Y., Noguchi, K., Ikeno, H., Fukae, R., Yamase, K., Makita, N., and Finer, L.: Applicability of the net sheet method for estimating fine root production in forest ecosystems, Trees-Struct. Funct., 30, 571-578, https://doi.org/10.1007/s00468-015-1308-y, 2016.

Ostonen, I., Lõhmus, K., and Pajuste, K.: Fine root biomass, production and its proportion of NPP in a fertile middleaged Norway spruce forest: comparison of soil core and ingrowth core methods, Forest Ecol. Manage., 212, 264-277, https://doi.org/10.1016/j.foreco.2005.03.064, 2005.

Pan, Y., Birdsey, R. A., Fang, J., Houghton, J. R., Kauppi, P. E., Kurz, W. A., Phillips, O., Shvidenko, A., Lewis, S. L., Canadell, J. G., Ciais, P., Jackson, R. B., Pacala, S. W., McGuire, D., Piao, S. W., Rautiainen, A., Sitch, S., Hayes, D., McGuire, A. D., Piao, S., Rautiainen, A., Sitch, S., and Hayes, D.: A large and persistent carbon sink in the world's forests, Science, 333, 988-993, https://doi.org/10.1126/science.1201609, 2011.

Park, J. H., Meusburger, K., Jang, I., Kang, H., and Alewell, C.: Erosion-induced changes in soil biogeochemical and microbiological properties in Swiss Alpine grasslands, Soil Biol. Biochem., 69, 382-392, https://doi.org/10.1016/j.soilbio.2013.11.021, 2014.

Pérez-Harguindeguy, N., Díaz, S., Garnier, E., Lavorel, S., Poorter, H., Jaureguiberry, P., Bret-Harte, M. S., Cornwell, W. K., Craine, J. M., Gurvich, D. E., Urcelay, C., Veneklaas, E. J., Reich, P. B., Poorter, L., Wright, I. J., Ray, P., Enrico, L., Pausas, J. G., de Vos, A. C., Buchmann, N., Funes, G., Quétier, F., Hodgson, J. G., Thompson, K., Morgan, H. D., ter Steege, H., van der Heijden, M. G. A., Sack, L., Blonder, B., Poschlod, P., Vaieretti, M. V., Conti, G., Staver, A. C., Aquino, S., and Cornelissen, J. H. C.: New handbook for standardised measurement of plant functional traits worldwide, Aust. J. Bot., 64, 715-716, https://doi.org/10.1071/BT12225_CO, 2016.

Phillips, O., Baker, T., Feldpausch, T., and Brienen, R.: RAINFOR Field Manual for Plot Establishment and Remeasurement, PanAmazonia, Gordon and Betty Moore Foundation, The Royal Society and European Research Council, Brussels, 22 pp., 2016.

Reichenbach, M., Fiener, P., Garland, G., Griepentrog, M., Six, J., and Doetterl, S.: The role of geochemistry in organic carbon stabilization against microbial decomposition in tropical rainforest soils, SOIL, 7, 453-475, https://doi.org/10.5194/soil-7-4532021, 2021.

Sahani, U. and Behera, N.: Impact of deforestation on soil physicochemical characteristics, microbial biomass and micro- 
bial activity of tropical soil, Land Degrad. Dev., 12, 93-105, https://doi.org/10.1002/ldr.429, 2001.

Schimel, D., Pavlick, R., Fisher, J. B., Asner, G. P., Saatchi, S., Townsend, P., Miller, C., Frankenberg, C., Hibbard, K., and Cox, P.: Observing terrestrial ecosystems and the carbon cycle from space, Glob. Change Biol., 21, 1762-1776, https://doi.org/10.1111/gcb.12822, 2015.

Schlüter, T. and Trauth, M. H.: Geological atlas of Africa: with notes on stratigraphy, tectonics, economic geology, geohazards and geosites of each country, Springer, Berlin, New York, 272 pp., 2006.

Ssali, H., Ahn, P. M., and Mokwunye, A. U.: Fertility of soils of tropical Africa: A historical perspective, in: Management of Nitrogen and Phosphorus Fertilizers in sub-Saharan Africa, edited by: Mokwunye, A. U. and Vlek, P. L. G., Martinus Nijhoff, Dodrecht, the Netherlands, 1986.

Summerauer, L., Baumann, P., Ramirez-Lopez, L., Barthel, M., Bauters, M., Bukombe, B., Reichenbach, M., Boeckx, P., Kearsley, E., Van Oost, K., Vanlauwe, B., Chiragaga, D., Heri-Kazi, A. B., Moonen, P., Sila, A., Shepherd, K., Mujinya, B. B., Van Ranst, E., Baert, G., Doetterl, S., and Six, J.: Filling a key gap: a soil infrared library for central Africa, SOIL Discuss. [preprint], https://doi.org/10.5194/soil-2020-99, in review, 2021.

Tang, J. and Riley, W.J.: Weaker soil carbon-climate feedbacks resulting from microbial and abiotic interactions, Nat. Clim. Change, 5, 56-60, https://doi.org/10.1038/nclimate2438, 2015.

Todd-Brown, K. E. O., Randerson, J. T., Post, W. M., Hoffman, F. M., Tarnocai, C., Schuur, E. A. G., and Allison, S. D.: Causes of variation in soil carbon simulations from CMIP5 Earth system models and comparison with observations, Biogeosciences, 10, 1717-1736, https://doi.org/10.5194/bg-10-1717-2013, 2013.

Trabucco, A. and Zomer, R. J.: Global aridity index and potential evapo-transpiration (ET0) climate database v2, CGIAR Consortium for Spatial Information (CGIAR-CSI), available at: https://cgiarcsi.community/2019/01/24/global-aridity-indexand-potential-evapotranspiration-climate-database-v2/ (last access: 1 October 2020), 2018.

Tyukavina, A., Hansen, M., Potapov, P., Parker, D., Okpa, C., Stehman, S. V., Kommareddy, I., and Turubanova, S.: Congo Basin forest loss dominated by increasing smallholder clearing, Science Advances, 4, eaat2993, https://doi.org/10.1126/sciadv.aat2993, 2018.

United Nations Educational, Scientific and Cultural Organization (UNESCO) and World Heritage Centre (WHC): World Heritage in the Congo Basin, Paris, France, available at: https://whc. unesco.org/en/conservation-congo-basin/ (last access: $10 \mathrm{Au}$ gust 2021), 2010. van Breugel, P., Kindt, R., Lillesø, J.-P. B., Bingham, M., Demissew, S., Dudley, C., Friis, I., Gachathi, F., Kalema, J., and Mbago, F. M.: Potential Natural Vegetation Map of Eastern Africa (Burundi, Ethiopia, Kenya, Malawi, Rwanda, Tanzania, Uganda and Zambia), Version 2.0, 2015.

Van Oost, K., Quine, T. A., Govers, G., De Gryze, S., Six, J., Harden, J. W., Ritchie, J. C., McCarty, G. W., Heckrath, G., Kosmas, C., Giraldez, J. V., Marques Da Silva, J. R., and Merckx, R.: The impact of agricultural soil erosion on the global carbon cycle, Science, 318, 626-629, https://doi.org/10.1126/science.1145724, 2007.

Veldkamp, E., Schmidt, M., Powers, J. S., and Corre, M. D.: Deforestation and reforestation impacts on soils in the tropics, Nat Rev. Earth Environ., 1, 590-605, https://doi.org/10.1038/s43017020-0091-5, 2020.

Verdooht, A. and Van Ranst, E.: Land evaluation for agricultural production in the tropics. A large-scale land suitability classification for Rwanda, Ghent University, Gent, Belgium, ISBN 9076769-89-3, 183 pp., 2003.

Verhegghen, A., Mayaux, P., de Wasseige, C., and Defourny, P.: Mapping Congo Basin vegetation types from $300 \mathrm{~m}$ and $1 \mathrm{~km}$ multi-sensor time series for carbon stocks and forest areas estimation, Biogeosciences, 9, 5061-5079, https://doi.org/10.5194/bg-9-5061-2012, 2012.

Vitousek, P. M.: Litterfall, nutrient cycling, and nutrient limitation in tropical forests, Ecology, 65, 285-298, 1984.

Walker, T. W. and Syers, J. K.: The fate of phosphorus during pedogenesis, Geoderma, 15, 1-19, https://doi.org/10.1016/00167061(76)90066-5, 1976.

Wilken, F., Fiener, P., Ketterer, M., Meusburger, K., Muhindo, D. I., van Oost, K., and Doetterl, S.: Assessing soil redistribution of forest and cropland sites in wet tropical Africa using 239+240Pu fallout radionuclides, SOIL, 7, 399-414, https://doi.org/10.5194/soil-7-399-2021, 2021.

Zanne, A. E., Lopez-Gonzalez, G., Coomes, D. A., Ilic, J., Jansen, S., Lewis, S. L., Miller, R. B., Swenson, N. G., Wiemann, M. C., and Chave, J.: Global wood density database, Dryad Digital Repository, http://datadryad.org/handle/10255/dryad.235 (last access: 1 February 2021), 2009. 